\title{
Low-carbon developments in Northeast China: evidence from cities
}

Xiaoyu Liu ${ }^{a, b}$, Zhiyaun Duan ${ }^{a, b}$, Yuli Shan ${ }^{c, *}$ Haiyan Duan ${ }^{a, b}$, Shuo Wang ${ }^{a, b}$, Junnian Song ${ }^{a, b}$, Xian'en Wang ${ }^{a, b, *}$

${ }^{a}$ Key Laboratory of Groundwater Resources and Environment, China's Ministry of Education, Jilin University, 130021 Changchun, PR China

${ }^{\mathrm{b}}$ College of New Energy and Environment, Jilin University, 130021 Changchun, PR China

${ }^{\mathrm{c}}$ School of Environmental Science and Tyndall Centre for Climate Change Research, University of East Anglia, NR4 7TJ, UK

*Corresponding authors: y.shan@uea.ac.uk (Yuli Shan) and wxen@jlu.edu.cn (Xian’en Wang) 


\section{Abstract}

Cities are a major source of energy use and greenhouse gases emissions, as well as being at the core of the climate change mitigation. With the Revitalizing Old Industrial Base of Northeast China strategy, Northeast China has been a typical developing region with rapid industrialization and urbanization accompanied by substantial energy consumption and carbon emissions. Therefore, northeastern Chinese cities should play an important role in regional lowcarbon developments. This study presents several improvements to previous method to improve the accuracy of the results. Using the modified method, for the first time, we compile carbon emission inventories for 30 cities in Northeast China based on fossil fuel combustion and industrial processes. The results indicate that Anshan emitted the most carbon emissions annually, followed by Benxi and the vice-provincial cities (including Changchun, Shenyang, Dalian and Harbin). In 2012, the total carbon emissions of the 30 cities amounted to 973.95 million tonnes, accounting for $9.71 \%$ and $2.75 \%$ of national and global carbon emissions, respectively. Most of the $\mathrm{CO}_{2}$ emissions of these cities were from the 'nonmetal and metal industry' and 'energy production and supply'. Raw coal was the primary source of carbon emissions in Northeast China, and industrial processes also played a significant role in determining the carbon emissions. Additionally, both the average per capita carbon emissions and carbon emission intensity in the 30 cities were higher than the national levels. According to the differences in carbon emissions characteristics, we present several policy recommendations for carbon mitigation for northeastern Chinese cities. This study provides consistent and comparable spatial-temporal city-level emission database for further research on 
relationships between economic development and environmental protection in Northeast China. Simultaneously, this study provides practical reference values for other developing regions throughout the world to create low-carbon road maps.

Keywords: Carbon emissions, Northeastern Chinese cities, Low-carbon developments, Emission intensity, Per capita emissions

\section{Highlights:}

$>\mathrm{CO}_{2}$ inventories of 30 cities in Northeast China were compiled for the first time.

$>$ We presented several improvements to previous method to improve the accuracy.

973.95 million tonnes were emitted in 2012 accounting for $9.71 \%$ of national levels.

$>$ Anshan emitted the most $\mathrm{CO}_{2}$ followed by Benxi and the vice-provincial cities.

$>$ Both the average per capita $\mathrm{CO}_{2}$ and $\mathrm{CO}_{2}$ intensity were higher than national levels.

\section{Introduction}

Forty years of reform and opening up have brought booming economic growth while simultaneously establishing China as the largest energy consumer and carbon dioxide $\left(\mathrm{CO}_{2}\right)$ emitter in the world [1, 2]. From 2010 to 2012 , approximately $75 \%$ of the increase in global carbon emissions from fossil fuel combustion and cement production was generated by China [3]. In 2016, 27.3\% of global $\mathrm{CO}_{2}$ emissions were released by China, which was 1.7 times 
greater than that of the United States [4]. Amid mounting international pressure, China has announced that its carbon emissions will peak by $2030[5,6]$. Contributing to global climate change mitigation, the government has pledged to reduce $\mathrm{CO}_{2}$ emissions per unit of gross domestic product (GDP) by $60 \%$ to $65 \%$ compared to 2005 levels by 2030 [7]. To achieve its national mitigation targets, China is expected to delegate the tasks to the sub-administrative regions, such as cities.

Cities are responsible for a large portion of energy consumption and carbon emissions. As reported by the Intergovernmental Panel on Climate Change (IPCC), cities consume 67-76\% of global energy and release approximately three-quarters of global $\mathrm{CO}_{2}$ emissions [8]. Additionally, energy-related carbon emissions will increase annually at a rate of $1.8 \%$ between 2006 and 2030 [9]. In China, 85\% of national carbon emissions are derived from energy consumption in cities, a share that is much higher than that generated in Europe (69\%) or in the United States (80\%) [10]. However, although cities are an important source of the climate change problem, they are also the key to solution [11]. Cities around the world are creating local mitigation polices and combining strengths in international efforts [12]. Additionally, compared with provinces and counties, cities in China are more flexible in carbon mitigation and policy implementation due to their relatively manageable size and governing capabilities via regulations and standards [13]. How to keep economic growth continually while at the same time curbing city-level carbon emissions is an important issue in China. To solve this problem, however, the first step is to develop a transparent and robust $\mathrm{CO}_{2}$ emission inventory associated with cities. 
The city-level carbon emission inventory has drawn great attention in global academic circles [14]. For example, Ramaswami et al. [15] developed a hybrid methodology to evaluate greenhouse gas (GHG) emissions from energy end-uses within city boundaries and six key cross-boundary activities, and their subsequent studies [16] applied this method to eight U.S. cities. Kennedy and colleagues $[17,18]$ compiled $\mathrm{CO}_{2}$ emission inventories incorporating electricity, heating and industrial fuel, ground transportation fuel, air and marine fuel, industrial processes and waste for ten global cities. Creutzig et al. [19] evaluated the aggregate potential for urban mitigation of global climate change using an energy/emission data set of 274 global cities. From a consumption-based perspective, Pichler et al. [20] employed a comparable approach to estimate urban GHG footprints for global cities, which included direct emissions from urban consumption activities and upstream emissions from the global production chain of locally consumed goods and services. Minx et al. [21] calculated the carbon footprints of the 434 municipalities in the UK.

Recently, more attention has been paid to Chinese cites' carbon emissions [14]. However, due to data limitations, studies mainly concentrated on large municipalities (Beijing, Tianjin, Shanghai and Chongqing) $[22,23]$, provincial capital cities $[24,25]$ and a few prefecture-level administrative divisions [26-28]. In order to solve this problem, Ramaswami et al. [29] calculated emissions from 637 Chinese cities by downscaling from national and provincial data to city level, Jing et al. [30] developed a top-bottom method to estimate city-scale energyrelated carbon emissions, and Cai et al. [31] used a bottom-up method to construct a systematic high resolution emission database for Chinese cities. However, city-level emissions estimated by these methods are not consistent and comparable with the national/provincial inventories 
because of various methods and scopes. To address this knowledge gap, Shan et al. [32] developed a unified and comparable approach for constructing $\mathrm{CO}_{2}$ emission inventories for generic Chinese cities. Using this methodology, Shan et al. [32] estimated the $\mathrm{CO}_{2}$ emissions from 182 Chinese cities and explored their emission reduction capacities, $\mathrm{Xu}$ et al. [33] compiled $\mathrm{CO}_{2}$ emission inventories for 18 central Chinese cities from six provinces, and Zhou at el. [34] analysed low-carbon development in 23 cities located in Guangdong-Hong KongMacao Greater Bay Area (GBA) and their surroundings. These studies have made great contributions to the field of carbon emission inventories for Chinese cities. However, to be applicable to all Chinese cities, the methodology must be discussed and verified in additional cases, such as cities in typical developing regions.

Due to its abundant natural resources and unique development history, Northeast China was developed to be the largest industrial base during the First Five-Year Plan period [35]. As a production base for coal, crude oil, cement, iron and steel, automobiles and machine tools, Northeast China was once the most highly developed region and has made outstanding contributions to China's economy. However, due to resource depletion, environmental pollution and business reconstruction, Northeast China went through a dramatic economic recession in 1990s. In response to this situation, the adoption of the Revitalizing Old Industrial Base of Northeast China strategy proposed in 2003 offered a great opportunity for this region to develop. Meanwhile, the economic resurgence of Northeast China heavily relied on fossil fuel and emitted substantial $\mathrm{CO}_{2}$. Under such circumstances, however, accelerating the economic growth while simultaneously curbing energy consumption and carbon emissions should attract considerable attention from policymakers and researchers. Massive studies have 
been made to investigate carbon emissions at the regional $[36,37]$ and provincial levels $[38$, 39], while studies on carbon emissions from northeastern Chinese cities are limited [40]. Considering the imbalanced levels of economic development and resource distribution, the patterns of energy consumption and carbon emissions vary throughout cities. Consequently, to a large extent, determining the $\mathrm{CO}_{2}$ emission inventories of cities located in Northeast China can intensively reflect the various carbon emission characteristics of cities in developing region all over the world.

Based on the aforementioned analysis, this study constructs $\mathrm{CO}_{2}$ emission inventories for cities in typical developing regions for the first time. We present several improvements in previous method developed by Shan et al. [32] to improve the accuracy of the calculation results. We put forward four cases for cities with limited crude oil activity data. Using this modified method, we estimate $\mathrm{CO}_{2}$ emissions for 30 cities in Northeast China from 2000 to 2015. In addition, we analyse the carbon emission characteristics of various fossil fuel types and socioeconomic sectors, and the variation of per capita carbon emissions and carbon emission intensity among different cities. According to the research outcomes, we offer several policy recommendations to reveal the carbon mitigation pathways for these cities. This study provides consistent and comparable spatial-temporal city-level emission database for further research on relationships between economic development and environmental protection in Northeast China. Moreover, this paper also aimed to provide practical reference value for other developing regions throughout the world to achieve sustainable development.

\section{Method and data sources}




\subsection{Case selection}

We selected 30 cities in Northeast China based on data availability. These 30 cities cover $90.12 \%$ of the total area of Northeast China, and the spatial distribution and industry composition of individual cities are shown in Fig 1. The total percentages of national GDP and population for these 30 cities were $7.86 \%$ and $6.73 \%$ in 2015 , respectively. These cities are at different stages of socioeconomic development. Shenyang, Changchun, and Harbin are the provincial capital cities of Liaoning, Jilin, and Heilongiiang Provinces, respectively. With the addition of Dalian, these four cities were defined as vice-provincial cities in 1994. The viceprovincial cities have province-level economic management authority, and these cities are generally larger and more affluent than other cities. In 2015, the total GDP and population of these four vice-provincial cities accounted for $48.77 \%$ and $32.84 \%$ of the 30 cities, respectively. Anshan and Benxi are important iron and steel industry base in China. Due to different resource endowments, Daqing, Panjin and Songyuan are petroleum bases, while Fuxin, Fushun Shuangya shan, Hegang and Jixi are coal bases in Northeast China. In addition, the per capita GDP of these 30 cities varied from 20,479 (Yichun) to 130,258 (Dalian) Chinese yuan (CNY) in 2015. Detailed socioeconomic characteristics are listed in Table 1. 


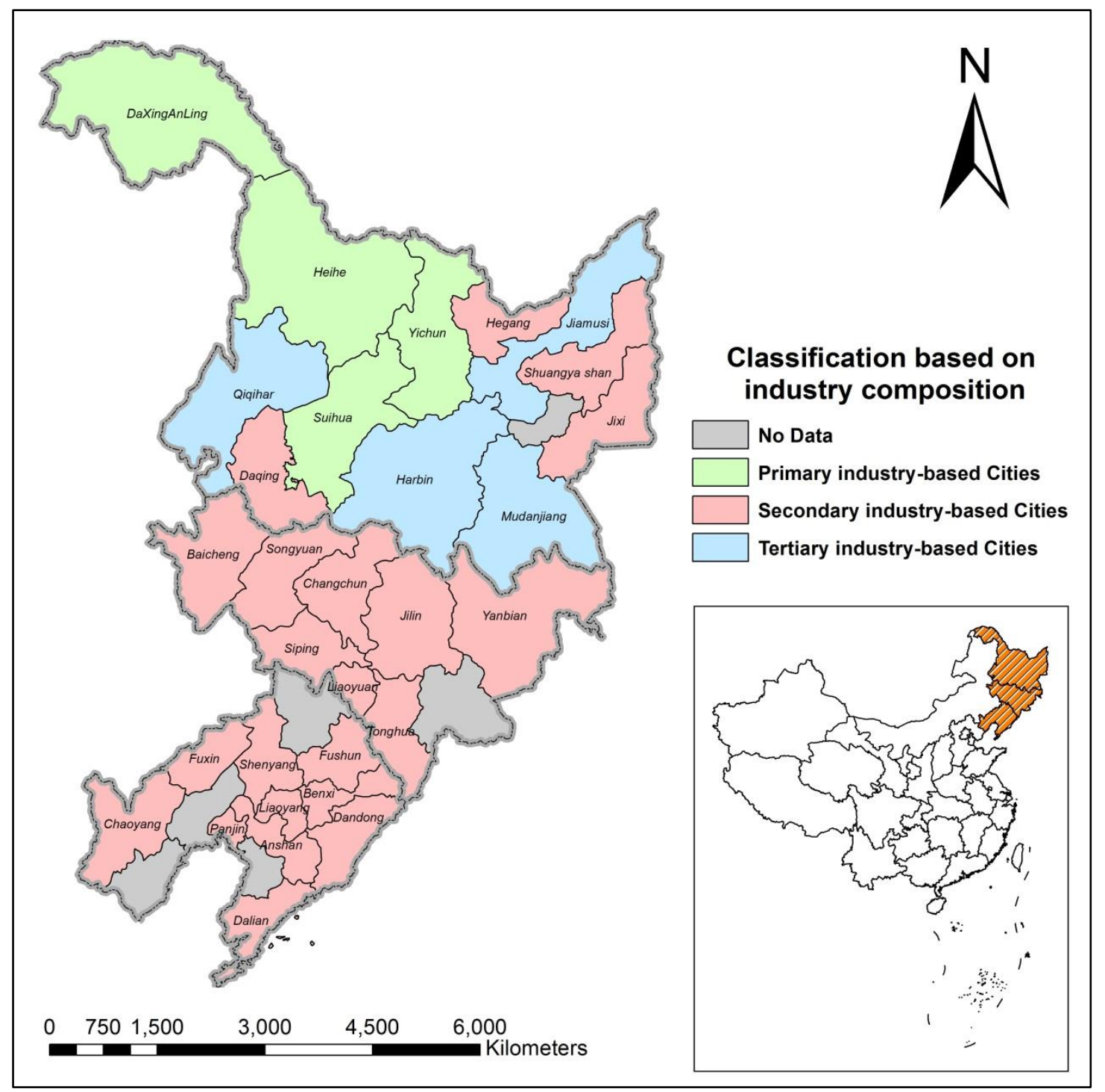

Fig. 1 Spatial distribution and industry composition of 30 cities in Northeast China

Table 1 The socioeconomic characteristics for 30 cities in Northeast China, 2015

\begin{tabular}{|c|c|c|c|c|c|c|}
\hline Province & City & $\begin{array}{l}\text { Land area } \\
\left(\mathrm{km}^{2}\right)\end{array}$ & $\begin{array}{l}\text { GDP } \quad\left(10^{4}\right. \\
\text { CNY })\end{array}$ & $\begin{array}{l}\text { Population } \\
\text { (persons) }\end{array}$ & $\begin{array}{ll}\text { GDP per } \\
\text { capita } & \\
(\mathrm{CNY}) & \end{array}$ & $\begin{array}{l}\text { Population } \\
\text { density } \\
\left(\text { persons } / \mathrm{km}^{2} \text { ) }\right.\end{array}$ \\
\hline \multirow[t]{10}{*}{ Liaoning } & Shenyang & 12860 & 72723051 & 7304051 & 99565 & 568 \\
\hline & Dalian & 12574 & 77316363 & 5935638 & 130258 & 472 \\
\hline & Anshan & 9255 & 23369966 & 3460500 & 67533 & 374 \\
\hline & Fushun & 11272 & 12164773 & 2157600 & 56381 & 191 \\
\hline & Benxi & 8411 & 11646927 & 1512100 & 77025 & 180 \\
\hline & Dandong & 15290 & 9849006 & 2381519 & 41356 & 156 \\
\hline & Fuxin & 10355 & 5255376 & 1894700 & 27737 & 183 \\
\hline & Liaoyang & 4788 & 10292000 & 1789600 & 57510 & 374 \\
\hline & Panjin & 4065 & 12565377 & 1295351 & 97004 & 319 \\
\hline & Chaoyang & 19698 & 8547329 & 3409000 & 25073 & 173 \\
\hline
\end{tabular}




\begin{tabular}{|c|c|c|c|c|c|c|}
\hline \multirow[t]{8}{*}{ Jilin } & Changchun & 20594 & 55300345 & 7538335 & 73359 & 366 \\
\hline & Jilin & 27711 & 23941860 & 4262431 & 56169 & 154 \\
\hline & Siping & 14382 & 12332487 & 3264062 & 37783 & 227 \\
\hline & Liaoyuan & 5140 & 7266404 & 1208035 & 60151 & 235 \\
\hline & Tonghua & 15612 & 10012129 & 2211100 & 45281 & 142 \\
\hline & Songyuan & 21089 & 16373003 & 2780700 & 58881 & 132 \\
\hline & Baicheng & 25759 & 6996822 & 1966700 & 35576 & 76 \\
\hline & Yanbian & 43329 & 8588402 & 2135757 & 40212 & 49 \\
\hline \multirow[t]{12}{*}{ Heilongjiang } & Harbin & 53076 & 57512000 & 9613743 & 59823 & 181 \\
\hline & Qiqihar & 42255 & 12703250 & 5493897 & 23122 & 130 \\
\hline & Jixi & 22494 & 5146868 & 1811696 & 28409 & 81 \\
\hline & Hegang & 14665 & 2656000 & 1056000 & 25152 & 72 \\
\hline & Shuangya shan & 22051 & 4333342 & 1474346 & 29392 & 67 \\
\hline & Daqing & 21219 & 29835000 & 2755000 & 108294 & 130 \\
\hline & Yichun & 32800 & 2481894 & 1211895 & 20479 & 37 \\
\hline & Jiamusi & 32470 & 8101676 & 2375499 & 34105 & 73 \\
\hline & Mudanjiang & 38827 & 13107000 & 2620419 & 50019 & 67 \\
\hline & Heihe & 66862 & 4476647 & 1679423 & 26656 & 25 \\
\hline & Suihua & 34873 & 12722076 & 5485000 & 23194 & 157 \\
\hline & DaXingAnLing & 64768 & 1350970 & 472416 & 28597 & 7 \\
\hline
\end{tabular}

\subsection{Construction of $\mathrm{CO}_{2}$ emission inventory}

\section{$\underline{2.2 .1 \text { Boundary and scope of } \mathrm{CO}_{2} \text { emission inventory }}$}

The boundary of a city and the scope of a carbon emission inventory should be clearly defined to ensure that the results are comparable. Generally, there are three common types of city boundaries in the literature: administrative boundaries (territorial or political boundaries of a city), functional boundaries (based on connections or interactions between areas), and morphological boundaries (according to the form or structure of land use, land cover or the built environment) [8]. The selection of boundaries often depends on the requirements of a particular study and greatly influences the analysis results.

According to the Greenhouse Gas Protocol and International Council of Local 
Environmental Initiatives (ICLEI), city-scale carbon accounting can be classified into 3 scopes: (1) all carbon emissions from activities within the city boundary; (2) carbon emissions embodied in electricity, steam and heat used within the city boundary but purchased from outside the city boundary; and (3) carbon emissions embodied in products and services consumed within the city boundary, but with the related emissions occurring outside the city boundary. In addition to Scopes 1, 2 and 3, consumption-based accounting (carbon footprint) is widely used for estimating city-scale emissions, which include all direct and indirect emissions from final consumption activities associated with a city [41, 42].

In accordance with the guidelines from the IPCC regarding the allocation of GHG emissions, the administrative territorial boundary (Scope 1 emissions within administrative boundaries) is considered the scope for each city's carbon emissions. By including the emissions from fossil fuel consumption and industrial processes, the emission inventory designed in this paper includes all administrative boundary territorial $\mathrm{CO}_{2}$ emissions from 47 sectors, 17 energy types, and 7 main industrial processes. Energy used as 'chemical raw material and losses during transportation' are removed from the total energy consumption to avoid double counting. Emissions from electricity and heat generated within the city boundary are counted based on the primary energy input usage, such as raw coal. Our administrative territorial emission inventory excludes emissions from imported electricity and heat consumption from outside the city boundary as well as inter-city transportation energy consumption. We only focus on fossil fuel consumed within the city boundary [32].

\section{$\underline{2.2 .1 \mathrm{CO}_{2}} \underline{\text { emissions from fossil fuel combustion }}$}


In this study, the carbon emissions from fossil fuel combustion are calculated for 47 socioeconomic sectors and 17 fossil fuels. The IPCC [43] sectoral approach is adopted to calculate the fossil fuel-related carbon emissions, as shown in Eq. (1).

$$
C E_{\text {energy }}=\sum_{j} \sum_{i} C E_{i j}=\sum_{j} \sum_{i} A D_{i j} \times N C V_{i} \times C C_{i} \times O_{i j}
$$

Here, $C E_{\text {energy }}$ represents the total carbon emissions from fossil fuel combustion. The subscript $j \in[1,47]$ denotes the socioeconomic sectors and $i \in[1,17]$ denotes the fossil fuel types [32]. $C E_{i j}$ indicates the carbon emissions from fossil fuel $i$ in sector $j . A D_{i j}$ refers to the activity data (energy consumption) of fossil fuel $i$ and sector $j ; N C V_{i}$ is the net caloric value, which is the heat value produced per physical unit of fossil fuel $i ; C C_{i}$ (carbon content) represents the carbon emissions per net caloric value produced by fossil fuel $i$; and $O_{i j}$ indicates the oxygenation efficiency, which is the oxidation radio during fossil fuel $i$. In this study, we adopt the emission factors recommended by Liu et al. [3], which are assumed to be more accurate than those from other organizations (such as the IPCC) and are widely used by other studies in China [44].

\section{$\underline{2.2 .2 \mathrm{CO}_{2} \text { emissions from industrial processes }}$}

In the current study, the process-related carbon emissions represent the $\mathrm{CO}_{2}$ emitted from chemical reactions in the production process, not that from the energy used by industry. Emissions from industrial processes are factored into the corresponding industrial sectors in the final emissions inventory. We calculate industrial process $\mathrm{CO}_{2}$ emissions in Eq. (2). 
$C E_{\text {process }}=\sum_{t} C E_{t}=\sum_{t} A D_{t} \times E F_{t}$

Here, $C E_{\text {process }}$ represents the total carbon emissions from industrial processes. The subscript $t \in[1,7]$ denotes industrial process [32]. $C E_{t}$ indicates the carbon emissions from industrial process $t$. $A D_{t}$ refers to the activity data (production of industrial process $t$ ), and $E F_{t}$ is the emission factor of industrial process $t$. Most of the emission factors of industrial processes are collected from the IPCC [43], while the emission factor for cement production which is 0.2906 tonne $\mathrm{CO}_{2} /$ tonne cement, is collected from Liu's previous study [3].

\subsection{Data collection}

The energy balance table (EBT), industry sectoral fossil fuel consumption and industrial product's production are the main data sources for estimating carbon emissions from both fossil fuel combustion and industrial processes. Generally, these data for cities can be collected from a city's statistical yearbooks. However, due to the poor data quality for China's cities, not all of the cities' statistical yearbooks contained all the required data. The detailed activity data requirements and calculation process were discussed in a previous study [32]. The annual GDP and population data for individual cities were obtained from the statistical yearbooks of the corresponding cities. Of special note, the GDP data in current prices were used in constructing $\mathrm{CO}_{2}$ emission inventories, while the data were converted into 2012 constant prices when analysing carbon emission intensity.

\subsection{Method improvements for cities without crude oil activity data}

Here, we present several improvements in methodology to attain more accurate results. 
The usage of crude oil can be roughly divided into two parts in the industrial production process: transformation usage in petroleum processing and combustion in other industrial processing. During petroleum processing, crude oil can be transformed into various petroleum products, such as gasoline, kerosene, diesel oil, fuel oil, liquefied petroleum gas and so on. The carbon emissions from the transformation of crude oil are excluded in this paper, as we consider only the carbon emissions from energy combustion. As in the previous method, the active data for crude oil are obtained from the EBT and industry sectoral energy consumption. In the EBT, 'Input \& Output of Transformation' for 'Petroleum Refineries' refers to the input of crude oil and output of petroleum products in petroleum processing. In the industry sector 'Petroleum Processing and Coking', crude oil consumption refers to the transformation usage of energy in petroleum processing. To avoid overestimation, the crude oil consumption in the 'Petroleum Processing and Coking' sector is subtracted from 'Input of Petroleum Refineries'. The crude oil consumption in other sectors is used to calculate carbon emissions. Most crude oil in 'Petroleum Processing and Coking' is used in the refining process, so that the data on 'Petroleum Processing and Coking' are extremely close to those of 'Input of Petroleum Refineries'. Referencing Dalian as an example, the crude oil data on 'Input of Petroleum Refineries' and 'Petroleum Processing and Coking' in 2013 were 23.15 and 23.17 Mt, respectively, a difference of only $0.02 \mathrm{Mt}$, accounting for $0.0864 \%$. In some cities, these two variables are equal, such as in Songyuan. However, due to poor data quality, some cities do not compile EBT or industry sectoral energy consumption data in their statistical yearbooks, and the crude oil data on 'Input of Petroleum Refineries' and 'Petroleum Processing and Coking' sector are deduced based on several cases from our previous study [32]. 
Every city has the 'Production of industrial products' table in its statistical yearbook, and this table includes a 'Crude oil processing quantity' category. We consider the value of 'Crude oil processing quantity' to be the same as that of 'Input of Petroleum Refineries'. Given the relationships in crude oil data between 'Petroleum Processing and Coking' and 'Input of Petroleum Refineries', we assume that the crude oil data in 'Crude oil processing quantity', 'Petroleum Processing and Coking' and 'Input of Petroleum Refineries' are equivalent. Accordingly, in the absence of data, any one of these three values can replace the other two for calculation. The following four cases cover all the possible crude oil data availabilities for Chinese cities (we assume that the energy consumption used in the following cases is for the whole industry; the discussion regarding industry enterprises above designated size and the whole industry can be found in our previous study [32]).

Case A: city with an EBT (or table of 'transformation usage of energy types) and industry sectoral energy consumption $\left(A D_{i j}\right)$. For certain cites, the crude oil data can be obtained from energy balance table (or table of 'transformation usage of energy types') and industry sectoral energy consumption. We use the data directly for emission estimation.

Case B: city with an EBT (or table of 'transformation usage of energy types'), but without industry sectoral energy consumption $\left(A D_{i j}\right)$. For cities such as Jilin, we can collect the total energy consumption by types from the statistical yearbooks. In this case, we first use 'Input of Petroleum Refineries' to replace 'Petroleum Processing and Coking', and then calculate the remaining crude oil in Eq. (3)

$C I_{\text {rem }}=C I_{\text {total }}-C I_{P P C}$ 
$C I_{\text {total }}$ refers to the total consumption of crude oil, $C I_{P P C}$ refers to crude oil used in the 'Petroleum Processing and Coking' sector, and $C I_{\text {rem }}$ refers to the remaining consumption of crude oil except for 'Input of Petroleum Refineries'. Next, we calculate the remaining consumption of crude oil $\left(\mathrm{CI}_{\mathrm{rem}}^{*}\right)$ at the provincial scale (or city scale in recent years). Finally, we divide $C I_{\text {rem }}$ into each sector by the multiplier $m_{C I}$ to obtain the consumption of crude oil in sectors $j$ ( $j$ is other sectors except for the 'Petroleum Processing and Coking' sector) (see Eq. (4)).

$C I_{j}=C I_{r e m} \times m_{C I}=C I_{r e m} \times C I_{j}^{*} / C I_{r e m}^{*}$

$C I_{j}$ refers to the consumption of crude oil in sectors $j ; C I_{j}^{*}$ is the consumption of crude oil in sectors $j$ at the provincial scale (or city scale in recent years); and $C I_{j}^{*} / C I_{r e m}^{*}$, which is the multiplier $m_{C I}$ in this paper, refers to the percentage of crude oil in sector $j$ to the total remaining crude oil at the provincial scale (or city scale in recent years).

Case C: city without an EBT (or table of 'transformation usage of energy types'), but with industry sectoral energy consumption $\left(A D_{i j}\right)$. For cities such as Panjin, we replace 'Input of Petroleum Refineries' with 'Petroleum Processing and Coking' in this case, while other data remain unchanged.

Case D: city with with neither an EBT (or table of 'transformation usage of energy types') nor industry sectoral energy consumption $\left(A D_{i j}\right)$. For cities such as Daqing, there are no crude oil data from EBT (or table of 'transformation usage of energy types) and industry sectoral energy consumption. In this case, we replace 'Crude oil processing quantity' with 'Input of 
Petroleum Refineries' and 'Petroleum Processing and Coking', and the subsequent manipulation is the same as in Case B.

With these four cases, we collect and deduce the crude oil consumption data for cities to ensure more accurate calculations of crude oil carbon emissions.

\section{Results}

\subsection{Temporal and spatial variations in $\mathrm{CO}_{2}$ emissions}

The data on carbon emissions caused by fossil fuel combustion and industrial processes for 30 northeastern Chinese cities from 2000 to 2015 are listed in Table 2. Due to a lack of available data, the carbon emissions of all cities were only complete for 2012 during the whole period. In total, 30 cities emitted 973.95 million tonnes (Mt) of $\mathrm{CO}_{2}$, and contributed approximately $9.71 \%$ and $2.75 \%$ of national and global carbon emissions in 2012 , respectively [45].

Fig. 2 presents the temporal and spatial variations in carbon emissions for 30 cities over the 16-year period. The spatial distribution of carbon emissions has remained almost stable. Among the 30 cities, Anshan emitted the largest amount of carbon emissions annually (from 71.03 Mt in 2001 to $132.11 \mathrm{Mt}$ in 2014), followed by Benxi (from 89.13 Mt in 2008 to 106.10 Mt in 2014). In 2012, the carbon emissions of Anshan and Benxi were 122.87 Mt and 104.82 Mt, accounting for $12.62 \%$ and $10.76 \%$ of the total, respectively. Additionally, the total carbon emissions from the four vice-provincial cities increased from $98.36 \mathrm{Mt}$ in 2000 to $253.24 \mathrm{Mt}$ in 2015, with a growth rate of $157.45 \%$. The carbon emissions from Changchun (69.94 Mt), 
Dalian (66.80 Mt), Harbin (62.94 Mt) and Shenyang (60.80 Mt) accounted for the second highest share of the total among the 30 cities in 2012 , with proportions of $7.18 \%, 6.86 \%, 6.46 \%$ and $6.16 \%$, respectively. With the addition of Jilin $(52.51 \mathrm{Mt})$ and Daqing $(40.36 \mathrm{Mt})$, the total proportion of the above cities was approximately $60 \%$ in 2012. It signified that these eight highemission cities played a primary role in total carbon emissions in Northeast China and that mitigation priorities should be facilitated in these cities. In contrast, the carbon emissions in certain cities, such as Yichun, Heihe and DaXingAnLing, were consistently less than $10 \mathrm{Mt}$ during study period. All these cities combined discharged 19.72 Mt in 2012, accounting for $2.03 \%$ of the total.

Table 2 Carbon emissions from 30 cities in Northeast China, million tons, 2000-2015

\begin{tabular}{|c|c|c|c|c|c|c|c|c|}
\hline City & 2000 & 2001 & 2002 & 2003 & 2004 & 2005 & 2006 & 2007 \\
\hline Shenyang & 20.97 & 21.94 & 21.38 & 23.87 & 27.69 & 35.41 & 48.91 & 48.48 \\
\hline Dalian & 27.30 & 26.78 & 27.05 & 30.38 & N/A & 43.23 & 50.50 & 56.49 \\
\hline Anshan & N/A & 71.03 & 75.51 & 76.50 & N/A & 92.76 & 101.88 & 107.52 \\
\hline Fushun & 15.88 & 21.96 & 15.71 & 17.62 & 20.69 & N/A & 25.55 & 26.82 \\
\hline Benxi & N/A & N/A & N/A & N/A & N/A & N/A & N/A & N/A \\
\hline Dandong & N/A & N/A & 7.16 & 7.72 & N/A & N/A & 10.40 & 11.42 \\
\hline Fuxin & 5.33 & 4.73 & $\mathrm{~N} / \mathrm{A}$ & $\mathrm{N} / \mathrm{A}$ & N/A & N/A & 17.34 & 22.75 \\
\hline Liaoyang & N/A & N/A & N/A & N/A & N/A & N/A & N/A & N/A \\
\hline Panjin & 8.91 & 9.33 & 10.81 & 9.27 & 9.67 & 11.37 & 11.42 & 12.07 \\
\hline Chaoyang & N/A & N/A & N/A & N/A & N/A & N/A & N/A & 24.68 \\
\hline Changchun & 23.29 & 26.01 & 25.39 & 26.46 & $\mathrm{~N} / \mathrm{A}$ & 36.22 & 39.59 & 45.12 \\
\hline Jilin & 17.15 & 18.69 & 20.27 & 23.07 & 26.80 & 30.25 & 31.21 & 36.71 \\
\hline Siping & 8.54 & 9.65 & 11.40 & 13.34 & 15.14 & 17.57 & 19.51 & 20.45 \\
\hline Liaoyuan & 2.20 & N/A & N/A & N/A & N/A & N/A & 4.87 & N/A \\
\hline Tonghua & N/A & $\mathrm{N} / \mathrm{A}$ & $\mathrm{N} / \mathrm{A}$ & N/A & $\mathrm{N} / \mathrm{A}$ & N/A & N/A & 18.81 \\
\hline Songyuan & N/A & N/A & N/A & N/A & N/A & N/A & 14.27 & 15.81 \\
\hline Baicheng & N/A & N/A & N/A & N/A & N/A & N/A & N/A & 4.29 \\
\hline Yanbian & 6.25 & 5.79 & 6.26 & 7.28 & N/A & N/A & N/A & 13.08 \\
\hline Harbin & 26.80 & 28.13 & 32.93 & 34.36 & N/A & 36.30 & 39.36 & 42.23 \\
\hline
\end{tabular}




\begin{tabular}{|c|c|c|c|c|c|c|c|c|}
\hline Qiqihar & 19.68 & 20.03 & 20.22 & 20.29 & 22.46 & 24.26 & 25.53 & 25.37 \\
\hline Jixi & N/A & N/A & N/A & N/A & N/A & N/A & 13.87 & 13.47 \\
\hline Hegang & N/A & N/A & N/A & N/A & N/A & N/A & N/A & N/A \\
\hline ShuangYashan & N/A & N/A & N/A & 6.31 & N/A & 10.01 & 15.29 & 18.75 \\
\hline Daqing & 21.77 & 23.33 & 21.86 & 24.80 & 25.28 & 31.56 & 33.48 & 33.10 \\
\hline Yichun & N/A & N/A & N/A & N/A & N/A & N/A & N/A & 7.94 \\
\hline Jiamusi & N/A & N/A & N/A & N/A & N/A & 10.22 & 10.05 & N/A \\
\hline Mudanjiang & 10.96 & 11.09 & 11.44 & 8.02 & 8.97 & 17.07 & 16.97 & 15.91 \\
\hline Heihe & N/A & N/A & N/A & N/A & N/A & N/A & N/A & N/A \\
\hline Suihua & N/A & N/A & N/A & N/A & N/A & N/A & N/A & N/A \\
\hline DaXingAnLing & N/A & N/A & N/A & N/A & N/A & N/A & 1.56 & N/A \\
\hline City & 2008 & 2009 & 2010 & 2011 & 2012 & 2013 & 2014 & 2015 \\
\hline Shenyang & 48.22 & 55.35 & 60.52 & 58.06 & 60.80 & 63.25 & 67.66 & 63.89 \\
\hline Dalian & 64.02 & 62.50 & 63.83 & 64.67 & 66.80 & 64.48 & 65.24 & 64.35 \\
\hline Anshan & N/A & 110.86 & 117.08 & 118.56 & 122.87 & 126.43 & 132.11 & N/A \\
\hline Fushun & 26.35 & 30.19 & 30.40 & 29.01 & 26.75 & 26.74 & $\mathrm{~N} / \mathrm{A}$ & $\mathrm{N} / \mathrm{A}$ \\
\hline Benxi & 89.13 & 99.38 & 102.51 & 105.84 & 104.82 & 107.17 & 106.10 & N/A \\
\hline Dandong & 11.20 & 11.44 & 11.73 & 12.53 & 11.78 & 13.41 & 12.25 & 12.19 \\
\hline Fuxin & N/A & 31.06 & 32.35 & 35.49 & 33.94 & N/A & 31.30 & 25.84 \\
\hline Liaoyang & N/A & N/A & 13.72 & 15.80 & 14.47 & 13.17 & 12.93 & 12.51 \\
\hline Panjin & 11.90 & 11.68 & 13.26 & 14.35 & 18.55 & 19.71 & 21.11 & 21.24 \\
\hline Chaoyang & 20.12 & 23.90 & 22.52 & 33.42 & 36.97 & 44.31 & 39.70 & N/A \\
\hline Changchun & 48.79 & 53.44 & 58.83 & 63.43 & 69.94 & 69.45 & 64.12 & 58.80 \\
\hline Jilin & 41.39 & 37.22 & 42.30 & 54.58 & 52.51 & 55.35 & 52.69 & 51.45 \\
\hline Siping & 23.83 & 22.16 & 22.40 & 23.35 & 21.16 & 21.38 & 22.23 & 20.09 \\
\hline Liaoyuan & 7.37 & 8.76 & 10.38 & 11.26 & 12.23 & 10.89 & 10.40 & 9.63 \\
\hline Tonghua & 23.88 & 24.34 & 25.78 & 23.30 & 22.59 & 24.77 & 25.96 & 24.93 \\
\hline Songyuan & 16.52 & 15.50 & N/A & 14.87 & 15.27 & 15.24 & 14.45 & N/A \\
\hline Baicheng & 5.08 & 3.84 & 5.49 & 10.25 & 9.99 & 10.16 & 9.74 & 9.67 \\
\hline Yanbian & 12.67 & 12.64 & 13.86 & 17.13 & 16.71 & N/A & 14.56 & 14.24 \\
\hline Harbin & 43.20 & 43.37 & 49.81 & 57.54 & 62.94 & 64.02 & 63.91 & 66.20 \\
\hline Qiqihar & 26.86 & 26.29 & 27.34 & 30.45 & 32.22 & 30.77 & 30.31 & 30.25 \\
\hline Jixi & 14.52 & 13.43 & 16.96 & 20.91 & 21.36 & 19.76 & 17.19 & 15.91 \\
\hline Hegang & N/A & 7.41 & 8.00 & N/A & 11.87 & 10.07 & 10.68 & N/A \\
\hline ShuangYashan & 20.29 & 27.31 & 23.47 & 24.72 & 24.58 & 24.11 & 22.54 & 21.77 \\
\hline Daqing & 34.45 & 36.76 & 37.30 & 39.65 & 40.36 & 44.70 & 46.88 & 46.04 \\
\hline Yichun & 7.78 & 9.08 & 9.97 & 9.36 & 9.41 & 8.94 & N/A & 6.68 \\
\hline Jiamusi & 8.60 & 9.64 & 11.61 & 11.02 & 11.81 & 11.51 & 14.78 & 16.65 \\
\hline Mudanjiang & 14.81 & N/A & N/A & 18.43 & 18.96 & 18.98 & 15.48 & 17.15 \\
\hline
\end{tabular}




\begin{tabular}{lrrrrrrrr} 
Heihe & N/A & 5.79 & 5.97 & 6.78 & 7.43 & 6.75 & 6.34 & 6.30 \\
Suihua & N/A & N/A & N/A & 10.53 & 12.00 & 12.32 & 11.68 & 12.26 \\
DaXingAnLing & N/A & N/A & N/A & 2.41 & 2.89 & 2.76 & 2.64 & 2.66 \\
\hline
\end{tabular}
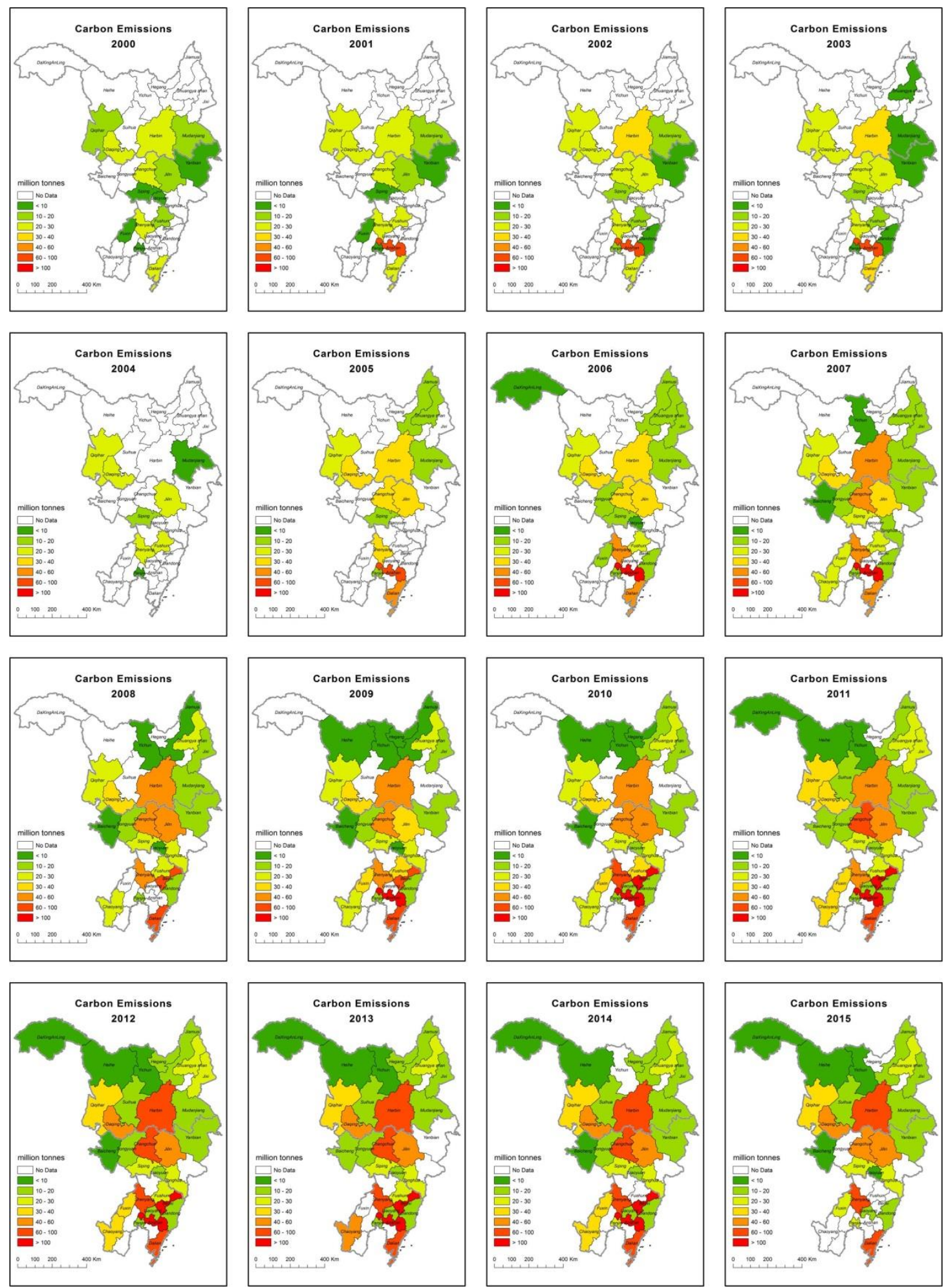

Fig. 2 Carbon emissions from 30 cities in Northeast China 
Additionally, the annual average growth rates (AAGRs) of carbon emissions for the 30 cities varied (Fig. 3). Most of the cities had positive AAGRs from 2000 to 2015, indicating that the carbon emissions from these cities exhibited an upward trend. Of these cities, the AAGRs for Fuxin, Baicheng, Liaoyuan, Shuangya shan, Shenyang, Jilin and Hegang were higher than the national level (7\%) [46, 47], with values of $11.10 \%, 10.69 \%, 10.33 \%, 8.09 \%, 7.71 \%, 7.60 \%$ and $7.59 \%$, respectively. Conversely, the carbon emissions from Yichun and Liaoyang showed a downward trend, with AAGRs of $-2.14 \%$ and $-1.83 \%$, respectively. The average AAGR was $8.69 \%$ from 2003 to 2009, which was higher than the growth rates in 2000-2003 (3.57\%) and 2009-2015 (2.59\%). Due to the Revitalizing Old Industrial Base of Northeast China strategy, the economy in Northeast China has been developing rapidly since 2003. Especially in 20032009 , the AAGR of GDP was $14.58 \%$, which was higher than those in $2000-2003(10.49 \%)$ and 2009-2015 (9.78\%). The AAGRs of GDP have similar trends as those of carbon emissions, indicating that carbon emissions have been greatly affected by the economy.

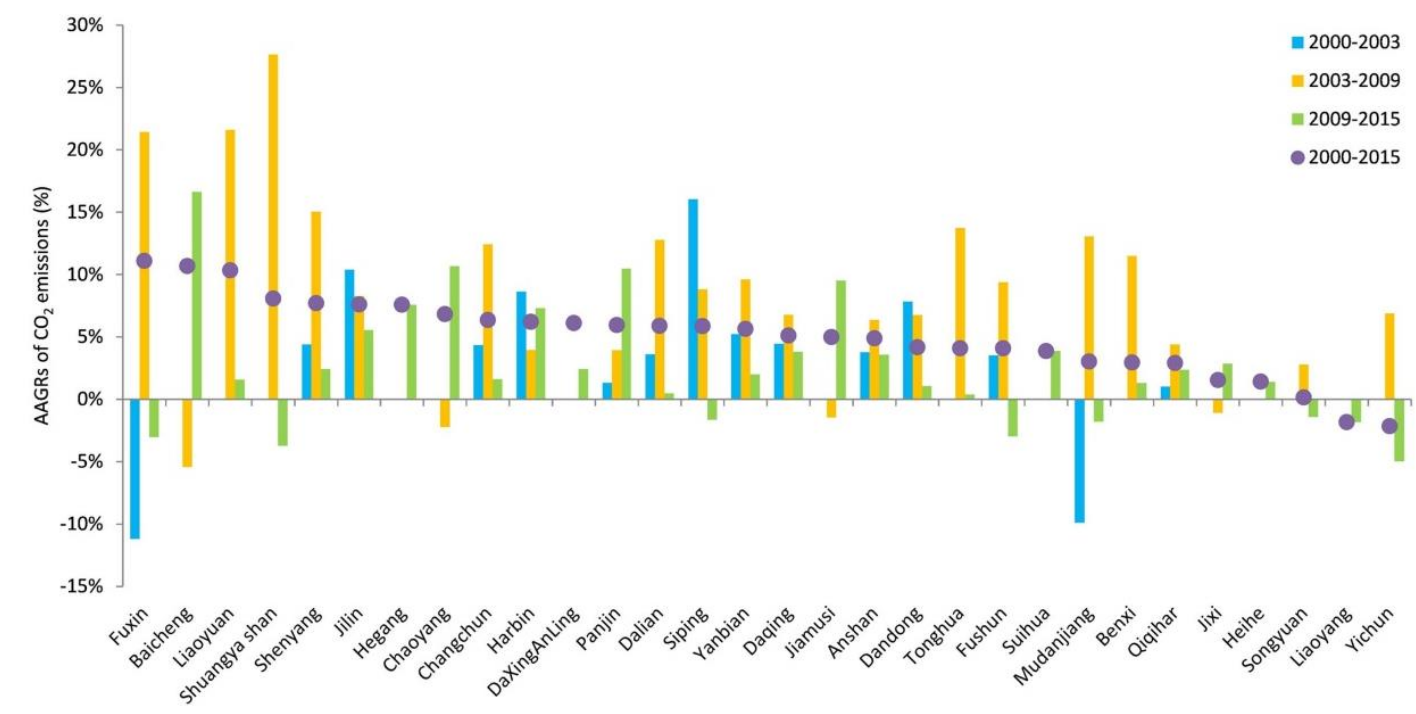

Fig. 3 AAGRs of carbon emissions for 30 cities in Northeast China 


\subsection{Uncertainty analysis}

Uncertainties caused by modeling input parameters have a potential significant impact on results [34]. Uncertainty analysis is an essential tool to improve emission inventories with uncertainties [48]. The major sources of uncertainty in this study mainly exist in activity data and emission factors. We assumed that both activity data and emission factors were normally distributed. The "uncertainty" refers to the intervals with lower and upper bounds of a certain confidence interval (CI) around our central estimates. The coefficients of variation (CVs) of activity data ranged from 5\% to $30 \%$ depending on sectors [49], and the CVs of emission factors were $3 \%, 1 \%$ and $2 \%$ for coal, oil and natural gas, respectively [3]. Monte Carlo method recommended by IPCC [43] was utilized to evaluate the uncertainties. We repeated the simulation procedure for 20,000 times.

The results showed that $95 \%$ uncertainties ( $d$ that ion procedure for 20,000 times. $r>20$ the 30 cities ranged from $-5.79 \%$ to $5.66 \%$. The average uncertainty of these cities $(-4.03 \%, 4.04 \%)$ was within the uncertainty range for non-OECD countries (10\%-20\%) [50], demonstrating that our results were relatively accurate and realizable. Looking at each city specifically, carbon emissions of Panjin had the lowest average uncertainty $(-2.23 \%, 2.23 \%)$, while emissions of Yanbian had the highest average uncertainty $(-5.38 \%, 5.41 \%)$. During the whole period, the highest uncertainty appeared in Siping in $2004(-5.64 \%, 5.79 \%)$, while the lowest uncertainty appeared in Panjin in 2001 (-1.67\%, 1.72\%).

\subsection{Comparison analysis}


Previous studies also explored the carbon emissions at the city level. Through the comparison analysis between this study and other's research, we can discern the merits and demerits of our current work. Xi et al. [40] calculated the GHG emissions of Shenyang in 2007. The total emission was $57 \mathrm{Mt}$, which was $19 \%$ higher than our result (48 Mt). The emission inventory in Xi's study covered three types of GHGs, including carbon dioxide $\left(\mathrm{CO}_{2}\right)$, methane $\left(\mathrm{CH}_{4}\right)$ and nitrogen oxide $\left(\mathrm{N}_{2} \mathrm{O}\right)$. Additionally, except for the in-boundary emissions from energy consumption and industrial process, the emission inventory also contained in-boundary emissions from products use, waste, and agriculture, forestry, and other land use, as well as outof-boundary emissions. Thus, this inventory provided more comprehensive information on citylevel emission status than our study. However, Xi et al. [40] only constructed emission inventory for Shenyang, whether this method can be used in other cities has not been discussed.

Using the input-output method, Mi et al. [42] estimated the consumption-based carbon emissions for 13 Chinese cities (including 3 cities studied in our work) in 2007. The consumption-based emissions of Harbin, Shenyang and Dalian were 55Mt, 74Mt and 59Mt, respectively, which were higher than the results in our study (42Mt, $48 \mathrm{Mt}$ and $56 \mathrm{Mt}$, respectively). Consumption-based accounting can explore not only direct emissions within city boundary but also indirect emissions from final consumption activities associated with a city. However, this method relies on city-level input-output data, which is rare for Chinese cities. Thus, consumption-based accounting has higher data requirements compared with the method in our study, making it difficult to implement.

Jing et al. [30] developed a top-bottom method to calculate the city-scale energy-related 
carbon emissions by downscaling from provincial energy consumption to the city level. They applied this method to estimate carbon emissions from 41 cities (including 5 cities studied in our work) in 2012. Table 3 shows the results and difference of energy-related carbon emissions between our study and Jing's research. Obviously, the difference of Harbin, Liaoyuan and Mudanjiang is within $10 \%$, while the difference of Panjin and Chaoyang is more than $30 \%$, indicating that carbon emissions of these cities have a high uncertainty. The top-bottom method relies on provincial energy data which is easily available. Therefore, this method has lower data requirements than our method making it can be applied to all Chinese cities. However, the energy mix and industrial structure are various across cities, and provincial dada cannot reflect the real situation of a city. Thus, the top-bottom method may contain higher uncertainty than our study.

Table 3 Comparison analysis of energy-related carbon emission estimations

\begin{tabular}{lrrr}
\hline City & Our estimation & Jing's estimation & Difference between two results \\
\hline Harbin & 60.01 & 66.77 & $-10 \%$ \\
Chaoyang & 31.66 & 14.95 & $112 \%$ \\
Liaoyuan & 12.23 & 13.05 & $-6 \%$ \\
Mudanjiang & 17.26 & 19.12 & $-10 \%$ \\
Panjin & 17.52 & 26.59 & $-34 \%$ \\
\hline
\end{tabular}

\section{Discussion}

\section{1 $\mathrm{CO}_{2}$ emissions from fossil fuel combustion and industrial processes}

In northeastern Chinese cities, most of carbon emissions were generated from fossil fuel, with an average percentage of $90.32 \%$ of the cumulative carbon emissions over the study period (Fig. 4(A)). Based on natural resource endowments, raw coal was the primary source of carbon 
emissions among the 17 energy types, representing an average of $57.81 \%$, followed by coke (8.67\%), diesel oil (6.81\%) and cleaned coal (6.73\%). Additionally, the carbon emissions from fossil fuel combustion varied among cities (Fig. 4(B)). In general, raw coal was the primary source of emissions in most cities, except for Anshan and Benxi. The carbon emissions from coke in these two cities were higher than those of 16 other energy types, accounting for $32.36 \%$ and $23.37 \%$ in Anshan and Benxi, respectively. Cleaned coal and other gas are also major contributors to carbon emissions of these two cities. Anshan and Benxi are iron and steel metropolises, and most of the emissions of coke, cleaned coal and other gas are emitted from the production of iron and steel. In 2012, the total production from iron and steel, including pig iron, crude steel and rolled steel, was 97.62 million tonnes in Anshan and Benxi, which accounted for $44.55 \%$ and $4.17 \%$ of the total production in Northeast China and national level, respectively. Thus, the carbon emissions from coke, cleaned coal and other gas were much higher than those in the other cities. The vice-provincial cities were important contributors to diesel oil-related emissions, with a share of $43.77 \%$ in 2012 . Diesel oil is wildly used in most types of transportation, such as vehicles and ships. The vice-provincial cities are important transport junctions in Northeast China, and they had relatively higher diesel oil consumption. The carbon emissions from natural gas in Panjin (24.77\%), Songyuan (18.39\%) and Daqing (14.87\%) showed notable differences from those in other cities $(<1.50 \%)$, which highlighted that the energy consumption structures in these cities were much cleaner.

Industrial processes also played an important role in carbon emissions in northeastern Chinese cities, with an average of $9.68 \%$ of cumulative carbon emissions during the period (Fig. 4(A)). In 2012, the total carbon emissions level produced by industrial processes in the 30 cities 
was $113.22 \mathrm{Mt}$, representing a contribution of $11.62 \%$ of the total emissions. Due to different industrial structures, the shares of industrial process emissions varied from $1.37 \%$ in Fuxin to $24.87 \%$ in Benxi, and most emissions were produced from the production of cement, iron and steel.

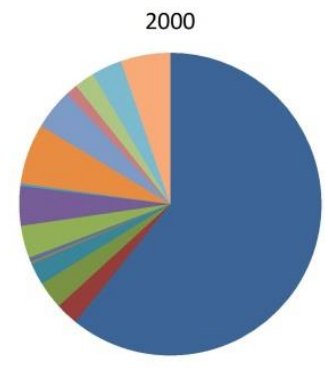

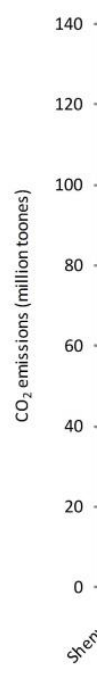

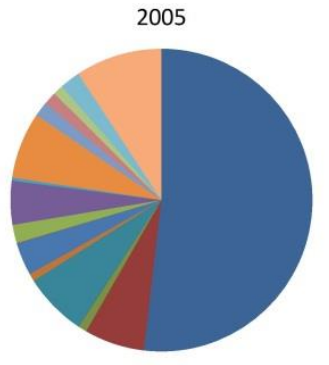

A

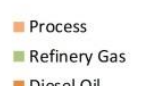

miesel Oil

= Crude Oil

- Coke Oven Gas

m Other Washed Coal

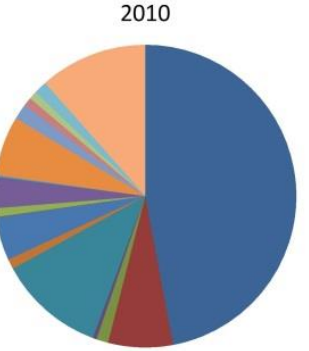

A n Natural Gas

$m$ LPG

= Kerosene

n Other Coking Products

n Coke

- Cleaned Coal

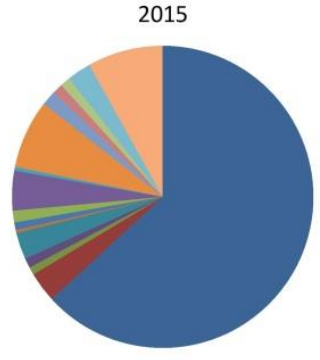

Other Petroleum Products

M Fuel Oil

- Gasoline

- Other Gas

- Raw Coal

Fig. 4 Percentages of cumulative carbon emissions by energy type and industrial process (\%) from 2000 to 2015 (A) and carbon emissions by energy type and industrial process from 30 cities in 2012 (B)

\section{2 $\mathrm{CO}_{2}$ emissions from socioeconomic sectors}

In this paper, we merged 47 socioeconomic sectors into 12 categories to analyse the carbon emissions from 30 cities in Northeast China (Table 4). Fig. 5(A) describes the components of the cumulative sectoral carbon emissions from 2000 to 2015. Clearly, the 'nonmetal and metal 
industry' and 'energy production and supply' are the two main sources of cumulative carbon emissions, accounting for an average of $31.94 \%$ and $29.12 \%$, respectively. The "petroleum and chemical industry', 'transportation' and 'mining' categories accounted for $8.93 \%, 6.38 \%$ and $5.87 \%$, respectively, on average. The remaining categories belonged to low carbon-intensity sectors with less than $5 \%$ of contributions to the cumulative carbon emissions over the 16 -year period.
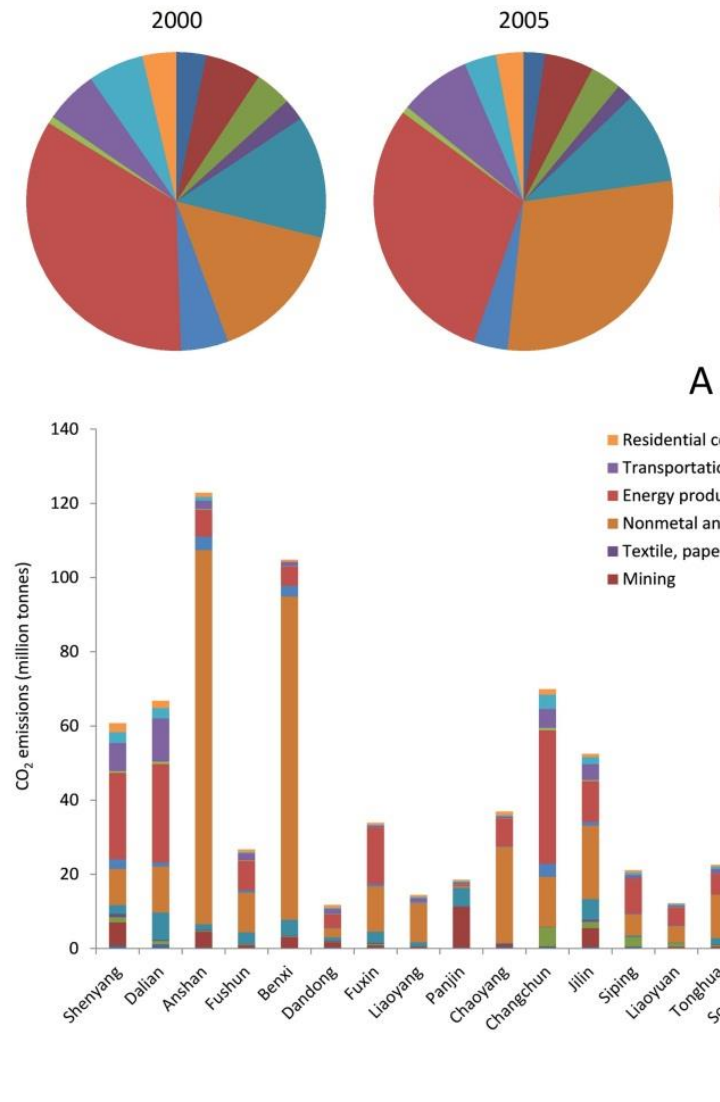

\section{A}

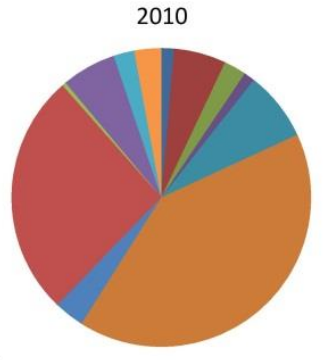

Residential consumption

uction and supply and matal industry extile, paper and wood industry

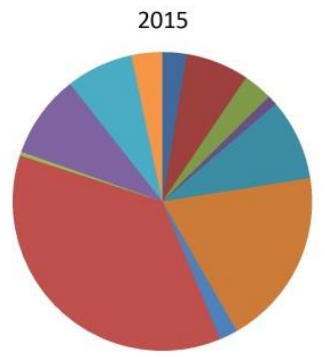

- Commercial industry and other services m Construction - Machinery - Petroleum and chemical industry m Food production - Primary industry

Fig. 5 Percentages of cumulative carbon emissions from socioeconomic sectors from 2000 to 2015 (\%) (A) and carbon emissions from socioeconomic sectors from 30 cities in 2012 (B)

Fig. 5(B) represents the distribution of carbon emissions by socioeconomic sectors for various cities in 2012. The carbon emissions from the 'nonmetal and metal industry' in Anshan and Benxi (100.87 Mt and 87.09 Mt, respectively) were higher than the total emissions of any other city (2.89-69.94 Mt). The production of cement, iron and steel contributed the most 
carbon emissions to the 'nonmetal and metal industry'. Amang the 30 cities, Anshan, Benxi, Chaoyang, Jilin and Tonghua emitted large amounts of $\mathrm{CO}_{2}$ from the 'smelting and pressing of ferrous metals', and Changchun, Dalian and Liaoyang emitted large amounts of $\mathrm{CO}_{2}$ from the 'nonmetal mineral products'. The carbon emissions generated from 'energy production and supply' played a dominant role in northeastern Chinese cities, especially in the vice-provincial cities, representing an average contribution of $43.34 \%$ to total emissions. Referencing Shenyang as an example, with the progression of urbanization, the percentage of 'energy production and supply' increased from $33.12 \%$ in 2000 to $44.82 \%$ in 2015 , representing the fastest growth rate among the vice-provincial cities. The sector of 'production and supply of electric power, steam and hot water' was the greatest contributor to 'energy production and supply'. Due to their geographical position and climate zones, cities in Northeast China usually have high energy consumption and emit considerable carbon emissions for winter heating. In addition, the carbon emissions from 'transportation' were higher in vice-provincial cities than those in other cities. Among these four cities, Shenyang, Changchun and Harbin are important inland transport junctions, and Dalian is the largest port in Northeast China. Particularly in Dalian, 'transportation' has been the second-largest source of carbon emissions since 2005, with an average percentage of $17.07 \%$ from 2000 to 2015 . There are 196 productive berths in Dalian harbour with 78 berths at the 10,000-tonne class and above; the cargo handled at seaports amounted to 374.26 million tonnes in 2012 , accounting for $3.84 \%$ of the national total.

Table 4 Final consumption sectors involved in city's energy statistics and $\mathrm{CO}_{2}$ emission inventory

\begin{tabular}{cll}
\hline No. & Socioeconomic sector & Category \\
\hline $\mathbf{1}$ & Farming, Forestry, Animal Husbandry, Fisheries and Water & Primary industry \\
& Conservancy & \\
\hline
\end{tabular}




\begin{tabular}{|c|c|c|}
\hline 2 & Coal Mining and Dressing & Mining \\
\hline 3 & Petroleum and Natural Gas Extraction & \\
\hline 4 & Ferrous Metal Mining and Dressing & \\
\hline 5 & Nonferrous Metal Mining and Dressing & \\
\hline 6 & Nonmetal Metal Mining and Dressing & \\
\hline 7 & Other Mineral Mining and Dressing & \\
\hline 8 & Logging and Transport of Wood and Bamboo & Food production \\
\hline 9 & Food Processing & \\
\hline 10 & Food Production & \\
\hline 11 & Beverage Production & \\
\hline 12 & Tobacco Processing & \\
\hline 13 & Textile Industry & Textile, paper and wood \\
\hline 14 & Garments and Other Fibre Products & industry \\
\hline 15 & Leather, Furs, Down and Related Products & \\
\hline 16 & Timber Processing, Bamboo, Cane, Palm Fibre \& Straw Products & \\
\hline 17 & Furniture Manufacturing & \\
\hline 18 & Papermaking and Paper Products & \\
\hline 19 & Printing and Record Medium Reproduction & \\
\hline 20 & Cultural, Educational and Sports Articles & \\
\hline 21 & Petroleum Processing and Coking & Petroleum and chemical \\
\hline 22 & Raw Chemical Materials and Chemical Products & industry \\
\hline 23 & Medical and Pharmaceutical Products & \\
\hline 24 & Chemical Fibres & \\
\hline 25 & Rubber Products & \\
\hline 26 & Plastic Products & \\
\hline 27 & Nonmetal Mineral Products & Nonmetal and metal industry \\
\hline 28 & Smelting and Processing of Ferrous Metals & \\
\hline 29 & Smelting and Processing of Nonferrous Metals & \\
\hline 30 & Metal products & \\
\hline 31 & Ordinary Machinery & Machinery \\
\hline 32 & Equipment for Special Purposes & \\
\hline 33 & Transportation Equipment Manufacturing & \\
\hline 34 & Electric Equipment and Machinery & \\
\hline 35 & Electronic and Telecommunications Equipment & \\
\hline 36 & Instruments, Meters, and Cultural and Office Machinery & \\
\hline 37 & Other Manufacturing Industry & \\
\hline 38 & Scrap and Waste & \\
\hline 39 & $\begin{array}{l}\text { Production and Supply of Electric Power, Stream and Hot Water } \\
\text { (Electricity Generation) }\end{array}$ & Energy production and supply \\
\hline 40 & Production and Supply of Gas & \\
\hline 41 & Production and Supply of Tap Water & \\
\hline 42 & Construction & Construction \\
\hline 43 & Transportation, Storage, Post and Telecommunication Services & Transportation \\
\hline 44 & Wholesale, Retail Trade and Catering Services & Commercial industry and other \\
\hline
\end{tabular}




\begin{tabular}{lll}
$\mathbf{4 5}$ & Others & services \\
\hline $\mathbf{4 6}$ & Urban & Residential consumption \\
$\mathbf{4 7}$ & Rural & \\
\hline
\end{tabular}

\subsection{Per capita $\mathrm{CO}_{2}$ emissions}

The per capita carbon emissions and AAGRs for the 30 cities are shown in Fig. 6. Most cities' per capita carbon emissions increased during the period except for Liaoyang and Yichun, which coincided with the downward trends in total carbon emissions. The per capita carbon emissions in 2012 ranged from $2.08 \mathrm{t}$ in Suihua to $68.42 \mathrm{t}$ in Benxi. The average per capita carbon emissions level among the 30 cities was $10.33 \mathrm{t}$, which was 1.62 times higher than that of China (6.38 t) [51]. The per capita carbon emissions in Benxi and Anshan far exceeded those of other cities in 2012 (Fig. 7). Although the total carbon emissions from Anshan and Benxi were approximately equal (122.87 Mt and 104.82 Mt, respectively), the population of Anshan was 2.29 times larger than that of Benxi, leading to a per capita carbon emissions level from Benxi was 1.95 times higher than that from Anshan, at $68.42 \mathrm{t}$ and $35.07 \mathrm{t}$, respectively. The second group includes 15 cities with per capita carbon emissions between 8 and 20 t. Most of these cities are primary energy suppliers (such as coal production in Fuxin, Shuangya shan, Fushun, Jixi and Hegang, and crude oil production in Panjin and Daqing) or heavy industry bases (such as Dalian, Shenyang, Changchun and Jilin). The third group includes 5 cities: Yanbian, Yichun, Mudanjiang, Siping and Haerbin. The per capita carbon emissions of these five cities were close to the national average. The remaining 8 cities belong to the low per capita carbon emissions group, indicating potentially increasing emissions due to further urbanization initiatives and improvements in residential living standards. 


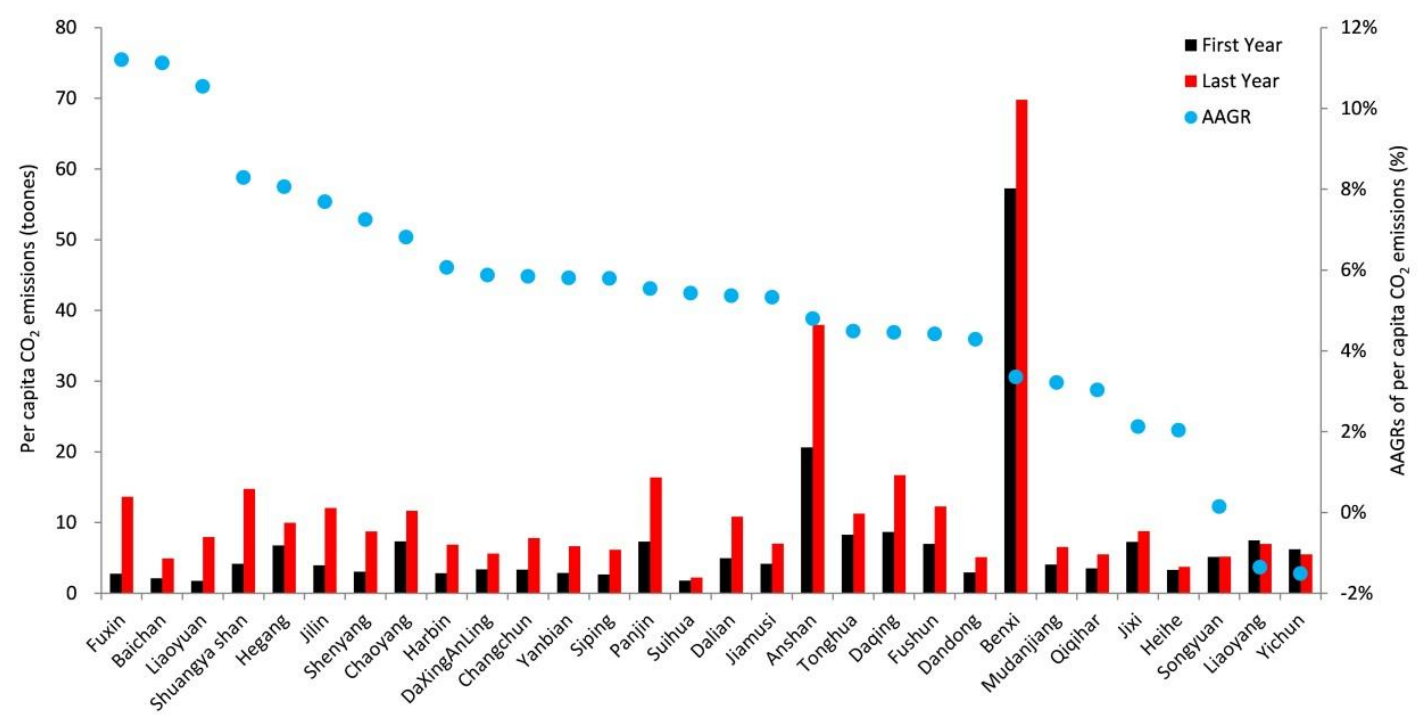

Fig. 6 Per capita carbon emissions (tonnes)and AAGRs (\%) for 30 cities in the first and last years from 2000 to 2015
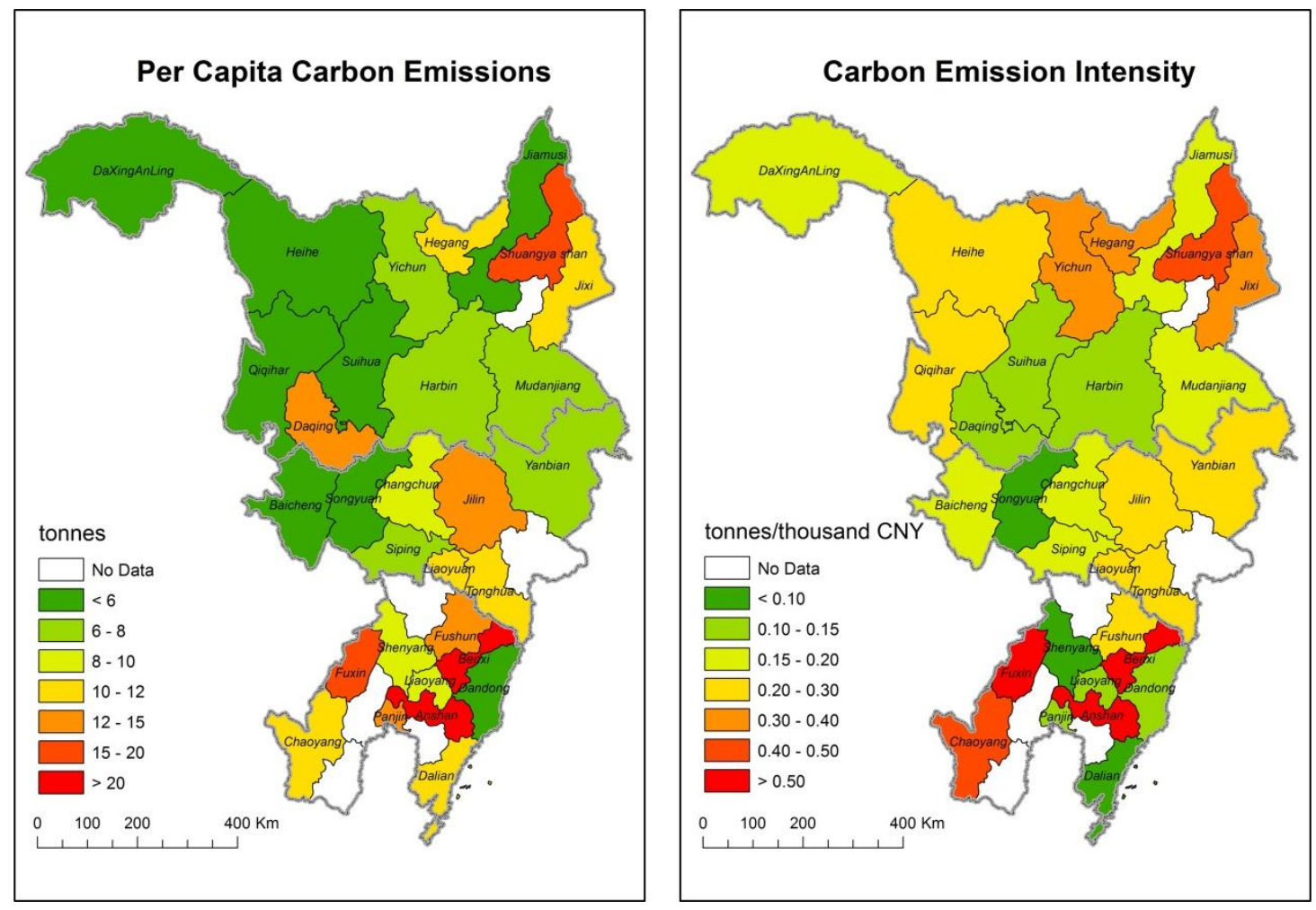

Fig. 7 Per capita carbon emissions (t) and carbon emission intensity (t/thousand CNY) for 30 cities in 2012

\section{4 $\mathrm{CO}_{2}$ emission intensity}

The carbon emission intensity varied among cities due to differences in development 
stages and development pathways (Fig. 8). In addition to Hegang and Shuangya shan, the carbon emission intensity exhibited a downward trend in the other cities. The primary reason for the increase in carbon emission intensity in Hegang and Shuangya shan is that the total carbon emissions grew faster than the GDP. The average carbon emission intensity among the 30 cities was $0.19 \mathrm{t} /$ thousand $\mathrm{CNY}$, which was higher than the national level $(0.15 \mathrm{t} /$ thousand CNY) [51]. The carbon emission intensities in vice-provincial cities were much lower than those in other cities, especially in Shenyang, which had the lowest carbon emission intensity among the 30 cities in 2012 (Fig. 7). However, the total carbon emissions and GDP in viceprovincial cities were higher than those in most cities, illustrating that more developed cities emitted higher total carbon emissions with lower carbon emission intensities.

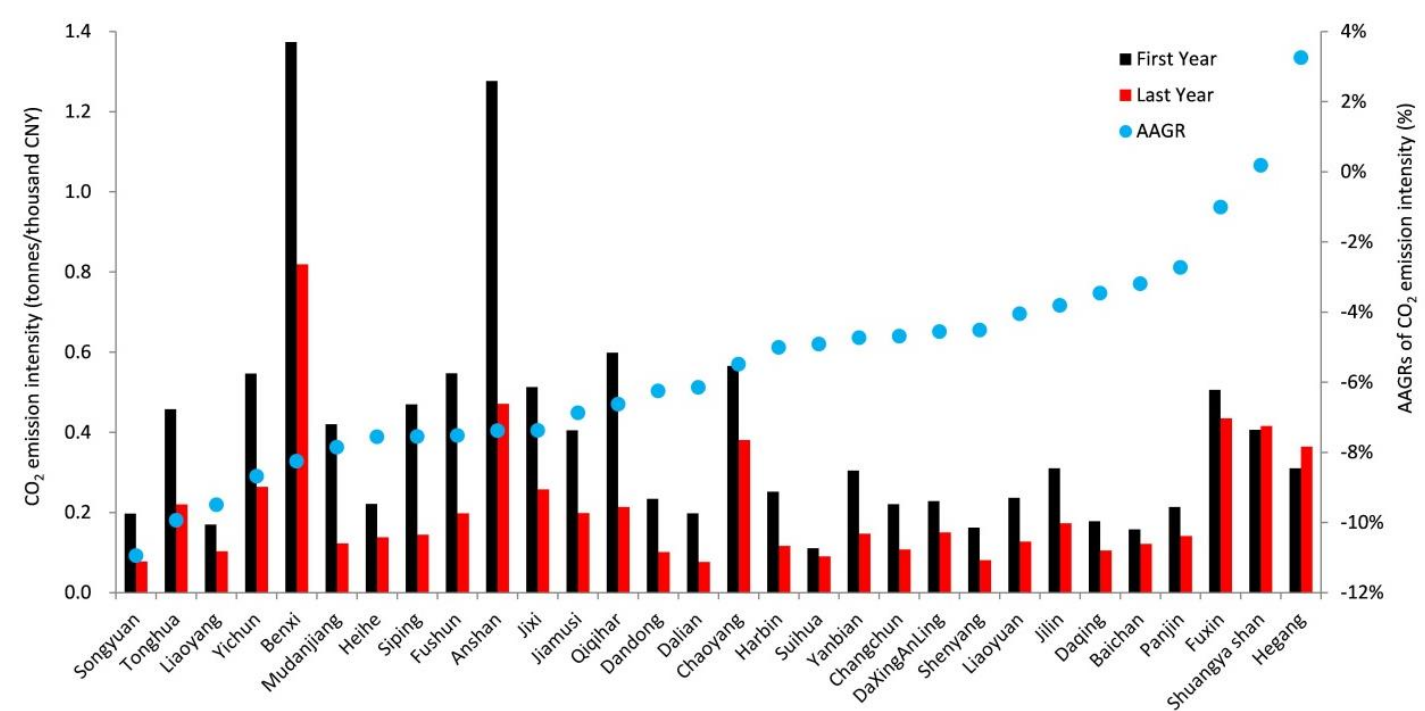

Fig. 8 Carbon emission intensities (t/103 CNY) and AAGRs (\%) for 30 cities for the first and last years from 2000 to 2015

China has promised to reduce $\mathrm{CO}_{2}$ emissions per unit GDP by $40-45 \%$ compared to 2005 levels by 2020 . As of 2013 , the $\mathrm{CO}_{2}$ emissions per unit GDP had fallen by $28.5 \%$ compared with 2005 levels [46]. To achieve China's national mitigation targets, all cities should make 
concerted efforts to complete the task ahead of time. In this study, there are 13 cities with available carbon emissions from 2005, and 9 of these cities achieved the target before 2015 (Fig. 9). Changchun and Shenyang reduced their $\mathrm{CO}_{2}$ emissions per unit GDP by over $40 \%$ in 2015, while Dalian completed the reductions by 2012. Harbin reduced the carbon emission intensity by $37.02 \%$ by 2015 , with the reduction rate of $4.11 \%$ per year. Thus, Harbin was expected to meet the national target by 2016 at the current annual rate. Although its carbon emissions were the highest among 30 cities, Anshan achieved the target ten years ahead of time. The main reason was that the GDP growth rate was faster than that of carbon emissions. Moreover, the share of GDP for tertiary industries in Anshan increased from 36.79\% in 2001 to $43.94 \%$ in 2014 , with an average percentage of nearly $40 \%$, which was higher than that in most heavy industrial cities. Therefore, the development of tertiary industries may not only improve the economic level of the city but also effectively reduce carbon emissions per unit GDP.

In 2015 , China adopted the target of reducing $\mathrm{CO}_{2}$ emissions per unit GDP by $60-65 \%$ based on 2005 levels by 2030. Among these cities, we determined that Siping and Mudanjiang completed the 2030 target in 2012 and 2013, respectively, and the emission intensity continued to decrease over the next few years. This finding indicated that these two cities will be able to emit greater carbon emissions in the next 15 years if economic development is necessary. The $\mathrm{CO}_{2}$ emissions per unit GDP in Shuangya shan fell by $16.52 \%$ during the past ten years, which was far behind the national schedule. At the current rate, Shuangya shan will not achieve the national targets in 2020 and 2030. Thus, Shuangya shan needs to make additional efforts to reduce the carbon mitigation rate in the future. 


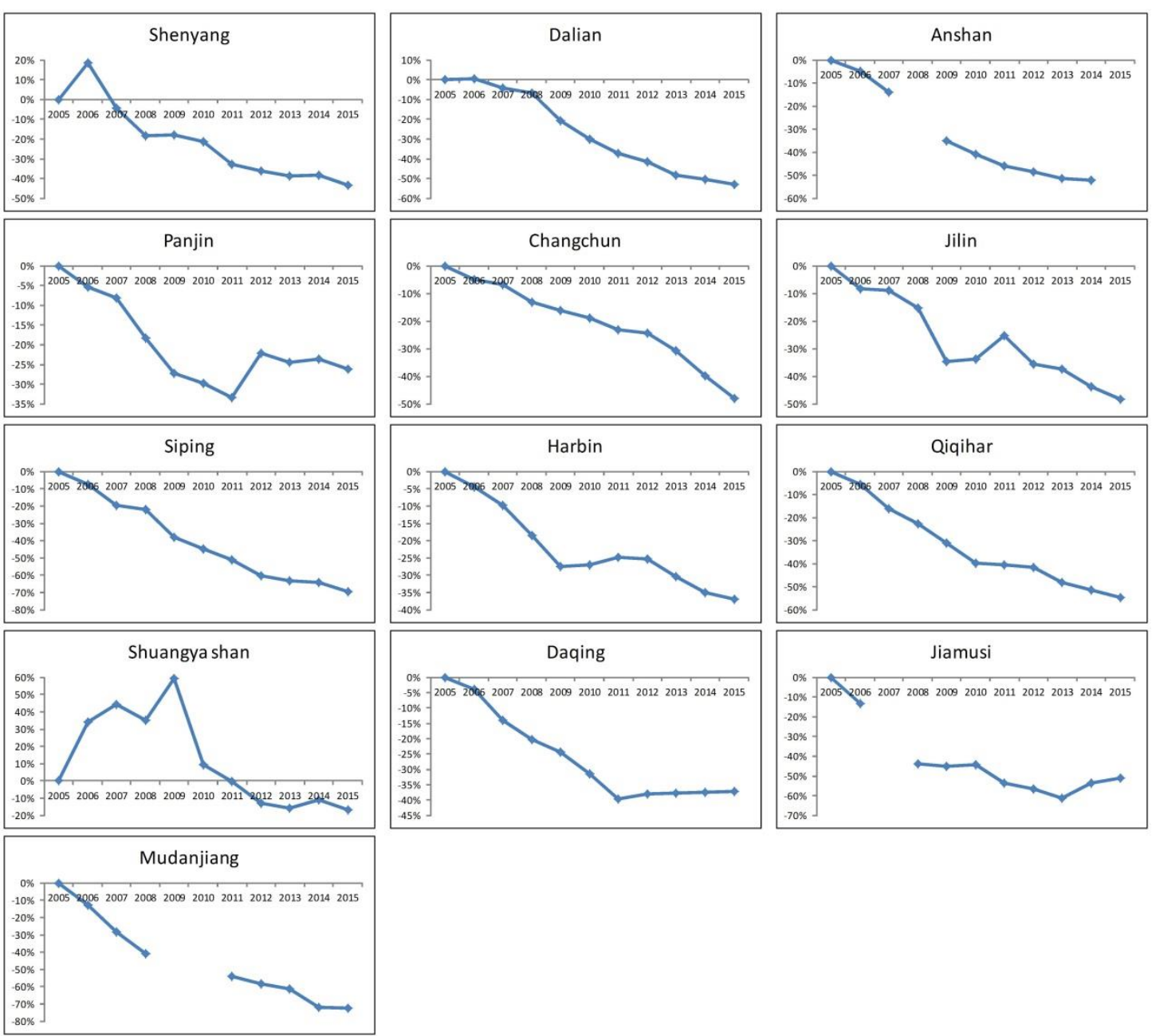

Fig. 9 Changes in $\mathrm{CO}_{2}$ emissions per unit GDP from 2005 to 2015 among 13 cities (levels for 2005 are set to 0 )

\section{Low-carbon development for cities in Northeast China}

As discussed above, the development stages and development pathways are varied in different cities, leading to large differences in economic levels, energy mixes and industrial structures. Thus, a single mitigation policy will not be suitable for all 30 cities in Northeast China, and polices should be adjusted according to the needs of individual cities. Here, based on the carbon situation of cities, we offer several policy recommendations for northeastern Chinese cities for carbon mitigation.

\subsection{Technical progress for cities producing raw materials}


Generally, cement, iron and steel are major raw materials for infrastructure construction, and they play an important role in the development of urbanization and industrialization. Moreover, cements, iron and steel are high carbon-intensity products [52, 53]. For raw materialproducing cities, such as Anshan, Benxi, Chaoyang, Tonghua and Liaoyang, more than 50\% of the total carbon emissions are generated by 'nonmetal and metal industry'. As a result, economic growth in these cities relies heavily on carbon-intensive industry. Thus, determining how to reduce carbon emissions from 'nonmetal and metal industry' while maintaining economic growth is the top priority for these cities.

Improving the technology level should be the primary policy for emission reduction. The government should increase direct investment in the development of energy-saving and lowemission production technology. Simultaneously, through special subsidies, lower taxes and other measures, the government should encourage enterprises to accelerate the elimination of backward production capacities with high $\mathrm{CO}_{2}$ emissions and low economic output. In addition, emission intensity targets should be supplemented by indicators of physical emission intensity. Referencing Anshan as an example, with the highest carbon emissions, Anshan achieved the national 2020 carbon-intensity target in 2010 (Fig. 9). At the current mitigation rate, Anshan is expected to meet the national 2030 carbon-intensity target ahead of schedule. Compared with other raw material-producing cities, however, Anshan's emissions have not shown a downward trend during the study period. Approximately $80 \%$ of carbon emissions came from 'nonmetal and metal industry'. Thus, indicators of physical emissions intensity, such as emissions per unit of steel production, will be useful to measure the mitigation efficiency of industrial sectors as well as for individual enterprises. 


\subsection{Reforming industrial structure and energy mix in the vice-provincial cities}

The vice-provincial cities are the core of socioeconomic development in Northeast China. As centres of wealth and innovation, more people and factories have occupied these cities, leading to higher electricity and heating consumption. The carbon emissions from 'energy production and supply' contributed the most to the total emissions in vice-provincial cities, and coal-related emissions played dominant role in this sector. Compared with oil and natural gas, coal emits more carbon emissions while producing the same amount of heat [54]. Reducing the share of coal in the energy mix and developing cleaner energy, such as renewable energy, will help emission control in these cities $[55,56]$.

Although Dalian, Shenyang and Changchun have achieved the national 2020 targets ahead of time, the per capita carbon emissions were still higher than the average national level. In addition, secondary industries remained mainstays in these cities. Reforming the industrial structure is an effective way to reduce carbon emissions and simultaneously maintain a higher rate of economic growth. The city government should shift the industry structure from heavy emission intensity manufacturing industries to service industries with lower emission intensities. Harbin was selected as a 'service outsourcing demonstration city' in 2009, and the percentage of tertiary industries has accounted for more than $50 \%$ since then. The potential for developing tertiary industries was lower than that of the other three cities. With relatively low per capita carbon emissions, Harbin should make efforts to reduce carbon emission intensity ahead of time. The vice-provincial cities are large manufacturing bases in China, such as Changchun First Automotive Works Corporation and Shenyang Aircraft Corporation. As pilot 
cities of 'Made in China 2025', Changchun and Shenyang will be crucial actors in realizing the China's strategic goal of becoming a powerful manufacturing country. Therefore, improving the technical level to reduce energy consumption per unit product will effectively reduce carbon emissions.

\subsection{Different low-carbon developments in primary energy-supply cities}

Due to various resource endowments, primary energy-supply cities in Northeast China can be divided into two groups: crude oil-supply cities (including Daqing, Panjin and Songyuan), and raw coal-supply cities (including Fuxin, Fushun, Shuangya shan, Hegang and Jixi). These cities have relatively higher per capita carbon emissions (Fig. 7), although the carbon emission characteristics are different. For crude oil-supply cities, most carbon emissions are generated from 'mining' and 'petroleum and chemical industry'. Due to the high price of petroleum, these cities are relatively more affluent than raw coal-supply cities, leading to much lower carbon emission intensities. Additionally, the energy consumption structures in these cities were much cleaner than those of other cities. In 2012, nearly $73 \%$ of natural gas-related emissions were generated from these three cities. Thus, for crude oil-supply cities, determining how to reduce the carbon emissions from 'mining' and 'petroleum and chemical industry' is the main task.

For raw coal-supply cities, most carbon emissions were generated from 'nonmetal and metal industry' and 'energy production and supply', which were the main coal-related emission sectors. Improving the technology level and shifting the energy mix will have a positive effect on carbon mitigation in these sectors. All of these coal-supply cities had relatively high carbon emission intensities, ranging between $0.22 \mathrm{t} / 10^{3} \mathrm{CNY}$ (Fushun) and $0.61 \mathrm{t} / 10^{3} \mathrm{CNY}$ (Fuxin) in 
2012. To achieve the national 2020 targets, reducing carbon emission intensity has been the main project in these cities. Therefore, reforming the industrial structure will be an effective measure for such situations. Furthermore, regional compensation mechanisms and carbon emissions trading would accelerate the mitigation efficiency in these cities, especially for Shuangya shan with a slow mitigation rate.

\subsection{Other policy recommendation for cities}

Cites with rapid carbon emission growth rates, such as Hegang, Liaoyuan, Shuangya shan and Jilin, should set controlling the rapid growth of carbon emissions as a priority target at fiveyear intervals. Cities with low per capita carbon emissions, such as DaXingAnLing, Baicheng, Heihe, Dandong and Suihua, which are located in remote areas and in less developed stages, should focus on economic development while controlling the growth of carbon emissions. Siping and Mudanjiang achieved the national 2030 carbon-intensity target before 2013, indicating that these cities have more room to emit carbon emissions according to economic development needs.

More developed cities such as Dalian and Changchun, which have reversed emissions growth since 2012, could adjust mitigation targets - for instance, reducing per capita carbon emissions to below those of the national level before 2030. While cities such as Harbin and Anshan, which emitted considerable $\mathrm{CO}_{2}$ emissions in past decades, did not reach their peaks before 2015, the earlier capping of these cities will be of great help in the fulfillment of China's peak carbon emission reduction goal approximately 2030. Emissions in underdeveloped cities such as Jiamusi and Hegang could be allowed to peak after 2030 to leave room for industrial 
development and infrastructure construction.

\section{Conclusions}

Cities are responsible for a large fraction of energy consumption and carbon emissions, and have been recognized as crucial actors in mitigating climate change throughout the world. The adoption of the Revitalizing Old Industrial Base of Northeast China strategy offered a great opportunity for Northeast China to develop. As a typical developing region, Northeast China has experienced rapid industrialization and urbanization accompanied by substantial energy consumption and carbon emissions. How to keep economic growth continually while at the same time reducing city-level carbon emissions is an important issue in this region. For such a process to be successful, however, the first step is to develop a transparent and robust $\mathrm{CO}_{2}$ emission inventory for northeastern Chinese cities.

In this paper, we construct $\mathrm{CO}_{2}$ emission inventories for cities in typical developing region for the first time. Based on the methodology developed by Shan et al. [32], we present several improvements in method by putting forward four cases for cities with limited crude oil activity data to improve the accuracy of the calculation results. Taking important Chinese developing region-Northeast China as a case, we estimate carbon emissions generated from fossil fuel combustion and industrial processes for 30 cities from 2000 to 2015 . The results showed that the carbon emissions varied among the cities and that most carbon emissions were concentrated in Anshan, Benxi, Changchun, Dalian, Shenyang, Harbin, Jilin and Daqing. In 2012, the total carbon emission level for the 30 cities was 973.95 million tonnes, accounting for $9.71 \%$ and $2.75 \%$ of national and global carbon emissions, respectively. Most carbon emissions were from 
energy types, and industrial processes also played an important role in carbon emissions in Northeast China. Additionally, the 'nonmetal and metal industry' and 'energy production and supply' categories contributed the most carbon emissions, followed by the 'petroleum and chemical industry', 'transportation' and 'mining' categories. Both the average per capita carbon emissions and carbon emission intensity were higher than the national levels. To reduce carbon emissions in these cities, we should improve the technical level of heavy industry, reduce the share of coal in the energy mix and shift the industry structure from heavy emission intensity manufacturing industries to services industries with lower emission intensities. This study provides consistent and comparable spatial-temporal city-level emission database for further research on relationships between economic development and environmental protection in Northeast China. Moreover, this paper also aimed to provide practical reference value for other developing regions throughout the world to achieve sustainable development.

However, this study still contains some limitations. First, due to data limitations, the emission inventories in this study only focus on scope 1 emissions, while the scope 2 and 3 , and consumption-based emissions cannot be estimated. Thus, current emission inventories do not contain comprehensive information associated with cities, and detailed explanation in terms of city-level emission status entails further work. Second, due to the lack of energy consumption data, some city's carbon emissions in individual years are missing. The carbon emissions of all 30 cities are only complete for 2012 during the whole period. Therefore, we fail to analyse the historical trajectory of total carbon emissions of these cities. Third, similar to crude oil in petroleum processing, there is no carbon emissions induced from the consumption of raw coal in coal dressing. However, how to improve the accuracy of carbon emission in sector 'coal 
mining and dressing' has not been well done. This is restrained by the data availability at genetic city scale. More detailed statistical data and site survey data may be helpful in calculation. Thus, further research will be conducted to improve the applicability of method and the accuracy of city's emission data.

\section{Acknowledgments}

This work is financially supported by China Clean Development Mechanism Fund [No. 2014031], National Social Science Fund of China [No. 15ZDA015] and Program of Key

Research Base of Humanities and Social Sciences, Ministry of Education of China [15JJD810010].

\section{References}

[1] Guan D, Peters GP, Weber CL, Hubacek K. Journey to world top emitter: An analysis of the driving forces of China's recent $\mathrm{CO}_{2}$ emissions surge. Geophys Res Lett. 2009;36.

[2] Liu Z, Guan DB, Crawford-Brown D, Zhang Q, He KB, Liu JG. A low-carbon road map for China. Nature. 2013;500:143-5.

[3] Liu Z, Guan DB, Wei W, Davis SJ, Ciais P, Bai J, Peng SS, Zhang Q, Hubacek K, Marland G, Andres RJ, Crawford-Brown D, Lin JT, Zhao HY, Hong CP, Boden TA, Feng KS, Peters GP, Xi FM, Liu JG, Li Y, Zhao Y, Zeng N, He KB. Reduced carbon emission estimates from fossil fuel combustion and cement production in China. Nature. 2015;524:335-+.

[4] BP, 2017. BP Statistical Review of World Energy.

[5] Mi ZF, Wei YM, Wang B, Meng J, Liu Z, Shan YL, Liu JR, Guan DB. Socioeconomic impact 
assessment of China's $\mathrm{CO}_{2}$ emissions peak prior to 2030. J Clean Prod. 2017;142:2227-36.

[6] Song JN, Yang W, Wang S, Wang XE, Higano Y, Fang K. Exploring potential pathways towards fossil energy-related GHG emission peak prior to 2030 for China: An integrated input-output simulation model.

J Clean Prod. 2018;178:688-702.

[7] NDRC. Enhanced actions on climate change: China's intended nationally determined contributions.

Department of Climate Change: Beijing;

2015.http://www4.unfccc.int/submissions/INDC/Published\%20Documents/China/1/China's\%20INDC

\%20-\%20on\%2030\%20June\%202015.pdf

[8] Seto KC, Dhakal S, Bigio A, Blanco H, Delgado GC, Dewar D, Huang L, Inaba A, Kansal A, Lwasa

S. Human Settlements, Infrastructure and Spatial Planning. Climate Change 2014: Mitigation of Climate

Change: Contribution of Working Group III to the Fifth Assessment Report of the Intergovernmental

Panel on Climate Change (IPCC, Geneva, Switzerland). 2014;Chap 12, pp 923-1000.

[9] International Energy Agency (IEA), 2009. Cities, Towns and Renewable Energy. Paris, France.

[10] Dhakal S. GHG emissions from urbanization and opportunities for urban carbon mitigation. Curr Opin Env Sust. 2010;2:277-83.

[11] Cai BF, Guo HX, Cao LB, Guan DB, Bai HT. Local strategies for China's carbon mitigation: An investigation of Chinese city-level $\mathrm{CO}_{2}$ emissions. J Clean Prod. 2018;178:890-902.

[12] Ottelin J, Heinonen J, Junnila S. Carbon footprint trends of metropolitan residents in Finland: How strong mitigation policies affect different urban zones. J Clean Prod. 2018;170:1523-35.

[13] Chen Q, Cai B, Dhakal S, Pei S, Liu C, Shi X, Hu F. CO 2 emission data for Chinese cities. Resources Conservation \& Recycling. 2017;126:198-208.

[14] Shan YL, Guan DB, Hubacek K, Zheng B, Davis SJ, Jia LC, Liu JH, Liu Z, Fromer N, Mi ZF, Meng 
J, Deng XZ, Li Y, Lin JT, Schroeder H, Weisz H, Schellnhuber HJ. City-level climate change mitigation in China. Sci Adv. 2018;4.

[15] Ramaswami A, Hillman T, Janson B, Reiner M, Thomas G. A Demand-Centered, Hybrid Life-Cycle Methodology for City-Scale Greenhouse Gas Inventories. Environ Sci Technol. 2008;42:6455.

[16] Hillman T, Ramaswami A. Greenhouse Gas Emission Footprints and Energy Use Benchmarks for Eight U.S. Cities. Environ Sci Technol. 2010;44:1902-10.

[17] Kennedy C, Steinberger J, Gasson B, Hansen Y, Hillman T, Havránek M, Pataki D, Phdungsilp A, Ramaswami A, Villalba Mendez G. Methodology for inventorying greenhouse gas emissions from global cities. Energ Policy. 2010;38:4828-37.

[18] Kennedy C, Steinberger J, Gasson B, Hansen Y, Hillman T, Havránek M, Pataki D, Phdungsilp A, Ramaswami A, Villalba MG. Greenhouse gas emissions from global cities. Environ Sci Technol. 2009;43:7297-302.

[19] Creutzig F, Baiocchi G, Bierkandt R, Pichler PP, Seto KC. Global typology of urban energy use and potentials for an urbanization mitigation wedge. Proc Natl Acad Sci U S A. 2015;112:6283-8.

[20] Pichler PP, Zwickel T, Chavez A, Kretschmer T, Seddon J, Weisz H. Reducing Urban Greenhouse Gas Footprints. Sci Rep-Uk. 2017;7:14659.

[21] Minx J, Baiocchi G, Wiedmann T, Barrett J, Creutzig F, Feng K, Förster M, Pichler PP, Weisz H, Hubacek K. Carbon footprints of cities and other human settlements in the UK. Environ Res Lett. $2013 ; 8: 035039$

[22] Liu Z, Liang S, Geng Y, Xue B, Xi FM, Pan Y, Zhang TZ, Fujita T. Features, trajectories and driving forces for energy-related GHG emissions from Chinese mega cites: The case of Beijing, Tianjin, Shanghai and Chongqing. Energy. 2012;37:245-54. 
[23] Sugar L, Kennedy C, Leman E. Greenhouse gas emissions from chinese cities. Journal of Industrial Ecology. 2012;16:552-63.

[24] Wang H, Zhang R, Liu M, Bi J. The carbon emissions of Chinese cities. Atmospheric Chemistry \& Physics. 2012;12:7985-8007.

[25] Dhakal S. Urban energy use and carbon emissions from cities in China and policy implications. Energ Policy. 2009;37:4208-19.

[26] Shan YL, Zheng HR, Guan DB, Li CM, Mi ZF, Meng J, Schroeder H, Ma JB, Ma ZG. Energy consumption and $\mathrm{CO}_{2}$ emissions in Tibet and its cities in 2014. Earths Future. 2017;5:854-64.

[27] Liang S, Zhang TZ. Managing urban energy system: A case of Suzhou in China. Energ Policy. 2011;39:2910-8.

[28] Fang K, Dong L, Ren JZ, Zhang QF, Han L, Fu HZ. Carbon footprints of urban transition: Tracking circular economy promotions in Guiyang, China. Ecol Model. 2017;365:30-44.

[29] Ramaswami A, Tong KK, Fang A, Lal RM, Nagpure AS, Li Y, Yu HJ, Jiang DQ, Russell AG, Shi L, Chertow M, Wang YJ, Wang SX. Urban cross-sector actions for carbon mitigation with local health cobenefits in China. Nat Clim Change. 2017;7:736-+.

[30] Jing QN, Bai HT, Luo W, Cai BF, Xu H. A top-bottom method for city-scale energy-related $\mathrm{CO}_{2}$ emissions estimation: A case study of 41 Chinese cities. J Clean Prod. 2018;202:444-55.

[31] Cai BF, Liang S, Zhou J, Wang JN, Cao LB, Qu S, Xu M, Yang ZF. China high resolution emission database (CHRED) with point emission sources, gridded emission data, and supplementary socioeconomic data. Resour Conserv Recy. 2018;129:232-9.

[32] Shan YL, Guan DB, Liu JH, Mi ZF, Liu Z, Liu JR, Schroeder H, Cai BF, Chen Y, Shao S, Zhang Q. Methodology and applications of city level $\mathrm{CO}_{2}$ emission accounts in China. $\mathrm{J}$ Clean Prod. 
$2017 ; 161: 1215-25$.

[33] Xu X, Huo H, Liu J, Shan Y, Li Y, Zheng H, Guan D, Ouyang Z. Patterns of $\mathrm{CO}_{2}$ emissions in 18 central Chinese cities from 2000 to 2014. J Clean Prod. 2018;172.

[34] Zhou Y, Shan YL, Liu GS, Guan DB. Emissions and low-carbon development in Guangdong-Hong Kong-Macao Greater Bay Area cities and their surroundings. Appl Energ. 2018;228:1683-92.

[35] ZHANG, Pingyu. Revitalizing Old Industrial Base of Northeast China: Process, Policy and Challenge. Chinese Geographical Science. 2008;18:109-18.

[36] Li H, Lo K, Wang M, Zhang P, Xue L. Industrial Energy Consumption in Northeast China under the Revitalisation Strategy: A Decomposition and Policy Analysis. Energies. 2016;9:549.

[37] Cheng H, Dong SC, Li FJ, Yang Y, Li ST, Li Y. Multiregional Input-Output Analysis of SpatialTemporal Evolution Driving Force for Carbon Emissions Embodied in Interprovincial Trade and Optimization Policies: Case Study of Northeast Industrial District in China. Environ Sci Technol. 2018;52:346-58.

[38] Tian X, Geng Y, Dong HJ, Dong L, Fujita T, Wang YT, Zhao HY, Wu R, Liu Z, Sun L. Regional household carbon footprint in China: a case of Liaoning province. J Clean Prod. 2016;114:401-11.

[39] Geng Y, Zhao HY, Liu Z, Xue B, Fujita T, Xi FM. Exploring driving factors of energy-related $\mathrm{CO}_{2}$ emissions in Chinese provinces: A case of Liaoning. Energ Policy. 2013;60:820-6.

[40] Xi FM, Geng Y, Chen XD, Zhang YS, Wang XB, Xue B, Dong HJ, Liu Z, Ren WX, Fujita T, Zhu QH. Contributing to local policy making on GHG emission reduction through inventorying and attribution: A case study of Shenyang, China. Energ Policy. 2011;39:5999-6010.

[41] Jones CM, Kammen DM. Quantifying Carbon Footprint Reduction Opportunities for U.S. Households and Communities. Environ Sci Technol. 2011;45:4088-95. 
[42] Mi Z, Zhang Y, Guan D, Shan Y, Liu Z, Cong R, Yuan X-C, Wei Y-M. Consumption-based emission accounting for Chinese cities. Appl Energ. 2016;184:1073-81.

[43] IPCC. 2006 IPCC Guidelines for National Greenhouse Gas Inventories. Intergovernmental Panel on Climate Change. 2006.

[44] Shan YL, Guan DB, Zheng HR, Ou JM, Li Y, Meng J, Mi ZF, Liu Z, Zhang Q. Data Descriptor: China $\mathrm{CO}_{2}$ emission accounts 1997-2015. Scientific Data. 2018;5.

[45] Carbon Dioxide Information Analysis Center (CDIAC). Fossil-fuel $\mathrm{CO}_{2}$ emissions. $<\underline{\text { http://cdiac.ornl.gov/trends/emis/meth_reg.html }>;} 2015$ [cited 2015].

[46] Liu Z, Guan DB, Moore S, Lee H, Su J, Zhang Q. Steps to China's carbon peak. Nature. 2015;522:279-81.

[47] Geng Y, Tian M, Zhu Q, Zhang J, Peng C. Quantification of provincial-level carbon emissions from energy consumption in China. Renew Sust Energ Rev. 2011;15:3658-68.

[48] Jonas M, Marland G, Krey V, Wagner F, Nahorski Z. Uncertainty in an emissions-constrained world. Climatic Change. 2014;124:459-76.

[49] Zhao Y, Nielsen CP, Lei Y, McElroy MB, Hao J. Quantifying the uncertainties of a bottom-up emission inventory of anthropogenic atmospheric pollutants in China. Atmos Chem Phys. 2011;11:2295308.

[50] Marland G. Uncertainties in accounting for CO(2) from fossil fuels. J Ind Ecol. 2008;12:136-9.

[51] Shan YL, Liu JH, Liu Z, Xu XWH, Shao S, Wang P, Guan DB. New provincial $\mathrm{CO}_{2}$ emission inventories in China based on apparent energy consumption data and updated emission factors. Appl Energ. 2016;184:742-50.

[52] Yang HZ, Liu JF, Jiang KJ, Meng J, Guan DB, Xu Y, Tao S. Multi-objective analysis of the co- 
mitigation of $\mathrm{CO}_{2}$ and PM2.5 pollution by China's iron and steel industry. J Clean Prod. 2018;185:33141.

[53] Xi FM, Davis SJ, Ciais P, Crawford-Brown D, Guan DB, Pade C, Shi TM, Syddall M, Lv J, Ji LZ, Bing LF, Wang JY, Wei W, Yang KH, Lagerblad B, Galan I, Andrade C, Zhang Y, Liu Z. Substantial global carbon uptake by cement carbonation. Nat Geosci. 2016;9:880-+.

[54] Li L, Chen C, Xie S, Cheng H, Zhen C, Wang H, Wang Y, Huang H, Lu J, Dhakal S. Energy demand and carbon emissions under different development scenarios for Shanghai, China. Energ Policy. 2010;38:4797-807.

[55] Song JN, Yang W, Higano Y, Wang XE. Introducing renewable energy and industrial restructuring to reduce GHG emission: Application of a dynamic simulation model. Energ Convers Manage. 2015;96:625-36.

[56] Wang HN, Wang XE, Song JN, Wang S, Liu XY. Uncovering regional energy and environmental benefits of urban waste utilization: A physical input-output analysis for a city case. J Clean Prod. 2018;189:922-32. 